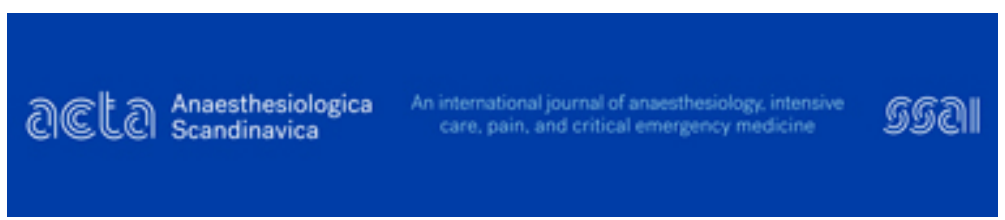

\title{
Utility of coagulation analyses to assess thromboprophylaxis with dalteparin in intensive care unit patients
}

\begin{tabular}{|r|l|}
\hline Journal: & Acta Anaesthesiologica Scandinavica \\
\hline Manuscript ID & AAS-20-0687.R1 \\
\hline Wiley - Manuscript type: & Clinical investigation \\
\hline Author: & n/a \\
\hline Complete List of Authors: & $\begin{array}{l}\text { Andersen, Nina; Oslo University Hospital, Departement og } \\
\text { Anaesthesiology } \\
\text { Mowinckel, Marie-Christine; Oslo University Hospital, Research Institute } \\
\text { of Internal Medicine; Oslo University Hospital, Department of } \\
\text { Haematology } \\
\text { Sunde, Kjetil; Oslo University Hospital, Department of Anaestesiology; } \\
\text { Universitetet i Oslo, Institute of Clinical Medicine } \\
\text { Sandset, Per Morten; University of Oslo, Institute of Clinical Medicine; } \\
\text { Oslo University Hospital, Department of Haematology } \\
\text { Beitland, Sigrid; University of Oslo, Renal Research Group Ullevål, } \\
\text { Faculty of Medicine }\end{array}$ \\
\hline Key Words: & $\begin{array}{l}\text { critical illness, venous thromboembolism, venous thrombosis, pulmonary } \\
\text { embolism, prophylaxis, dalteparin, biomarker }\end{array}$ \\
\hline Subject area: & \begin{tabular}{l} 
Intensive Care Medicine \\
\hline
\end{tabular} \\
\hline
\end{tabular}


Title

\title{
Utility of coagulation analyses to assess thromboprophylaxis with
}

\section{dalteparin in intensive care unit patients}

\author{
Names of the authors \\ Nina Gjerde Andersen ${ }^{1}$, Marie-Christine Mowinckel ${ }^{2,3}$, Kjetil Sunde ${ }^{1,4}$, Per Morten Sandset ${ }^{3,4}$, \\ Sigrid Beitland ${ }^{5}$
}

The name and location of the institutions where the work was carried out

1. Departement og Anaesthesiology, Oslo University Hospital, Oslo, Norway

2. Research Institute of Internal Medicine, Oslo University Hospital, Oslo, Norway

3. Department of Haematology, Oslo University Hospital, Oslo, Norway

4. Institute of Clinical Medicine, Universitetet i Oslo, Oslo, Norway

5. Renal Research Group Ullevål, Faculty of Medicine, University of Oslo, Oslo, Norway

\section{Short title \\ Coagulation analyses and dalteparin}

\section{Word count}

2947

Name, job title and address of the author to whom correspondence should be addressed Sigrid Beitland

$\mathrm{MD}, \mathrm{PhD}$, Postdocoral researcher

Renal Research group Ullevål, Faculty of Medicine, University of Oslo

Box 1072, Blindern, Oslo

Telephone: +4799040594 , Telefax: +4722119634

e-mail: sigrid.beitland@medisin.uio.no

\section{Conflict of interest}

The authors declare that they have no conflict of interest in relation to this manuscript. 


\begin{abstract}
Background: The aim of this study was to evaluate the utility of coagulation analyses to assess thromboprophylaxis with dalteparin in intensive care unit (ICU) patients.

Methods: Prospective observational study of ICU patients receiving dalteparin prophylaxis at Oslo University Hospital in Norway. Trough and peak antithrombin (AT), protein C (PC), anti-factor Xa activity (aFXa), d-dimer, thromboelastography (TEG), calibrated automated thrombogram (CAT) and microparticles (MPs) were analysed. Levels were compared in patients with and without venous thromboembolism (VTE), major bleeding, acute kidney injury (AKI) with use of renal replacement therapy (RRT) and variable dalteparin dose.
\end{abstract}

Results: Among 50 included patients ( $76 \%$ male, mean age 62 years) five (10\%) developed VTE and eight (16\%) major bleeding. Median through aFXa level was $0.03(0.02-0.05)$ $\mathrm{IU} / \mathrm{ml}$, and $48(96 \%)$ of patients were within and two (4\%) above target range. Peak aFXa level was $0.21(0.13-0.29) \mathrm{IU} / \mathrm{ml}$, the number of patients below, within and above prophylactic range were $21(42 \%), 25(50 \%)$ and four (8\%). Peak aFXa levels were similar in patients with and without VTE ( 0.18 vs $0.21 \mathrm{IU} / 1, \mathrm{p}=0.72)$, major bleeding (0.22 vs. $0.21 \mathrm{IU} / \mathrm{ml}, \mathrm{p}=0.38)$ and AKI with RRT (0.18 vs. $0.24, \mathrm{p}=0.13)$, but lower in patients receiving dalteparin $5000 \mathrm{IU}$ od compared to $7500 \mathrm{IU}$ od $(0.19$ vs $0.30 \mathrm{IU} / \mathrm{ml}, \mathrm{p}<0.01)$.

Conclusions: ICU patients receiving dalteparin prophylaxis had half of patients within prophylactic peak aFXa target range. Peak aFXa levels was affected by administered dalteparin dose, but not presence of VTE, major bleeding or AKI with RRT.

Keywords: critical illness, venous thromboembolism, venous thrombosis, pulmonary embolism, prophylaxis, dalteparin, biomarker 


\section{Introduction}

Deep vein thrombosis (DVT) and pulmonary embolism (PE) are common complications in intensive care unit (ICU) patients associated with adverse patient outcomes. ${ }^{1,2}$ Current guidelines therefore recommended the use of pharmacological thromboprophylaxis with lowmolecular-weight heparin (LMWH). ${ }^{1,3}$ Despite the use of prophylaxis, the incidence of venous thromboembolism (VTE) is relatively high, ${ }^{4,5}$ and use of LMWHs may cause severe bleeding. ${ }^{6}$ There is an ongoing debate about the efficacy and safety of such prophylaxis, including choice of drug, dose and individual patient adjustment. ${ }^{7}$

Biomarkers are developed to monitor coagulation, these include antithrombin (AT), protein C (PC), anti-factor Xa activity (aFXa), d-dimer, thromboelastography (TEG), calibrated automated thrombogram (CAT) and microparticles (MPs). ${ }^{7,8}$ When LMWH prophylaxis is monitored using aFXa levels, ${ }^{7-9}$ peak levels are thought to reflect VTE prophylactic properties (efficacy), whereas trough levels are thought to reflect bleeding tendency (safety). ${ }^{7}$ Challenges are lack of well standardized coagulation tests, target levels, and low correlation between test results and clinical outcomes. ${ }^{7}$ The interpretation of results is also challenging due to the heterogeneity of ICU patients and different pharmacological profiles of LMWHs. ${ }^{7}$ Routine monitoring of LMWH effect is therefore not recommended but might be useful in situations with altered LMWH pharmacokinetics. ${ }^{1,10}$

The primary aim of the study was to use coagulation analyses (AT, PC, aFXa, TEG, CAT and MPs) to assess thromboprophylaxis with dalteparin in ICU patients. Secondary aims were to explore if coagulation analyses were correlated to VTE, major bleeding, presence of acute kidney injury (AKI) with use of renal replacement therapy (RRT) or administered dalteparin dose. Our hypothesis was that peak coagulation analyses was correlated to administered dalteparin doses. 


\section{Methods}

\section{Study design and setting}

The study was a pre-planned sub-study of the prospective observational Norwegian Intensive Care Unit Dalteparin Effect Study (NORIDES study). ${ }^{11}$ The objective of the NORIDES study was to investigate dalteparin prophylaxis in ICU patients, and if presence of AKI with RRT influenced clinical and biochemical outcomes. Oslo University Hospital is a community hospital for Oslo, and a regional hospital for 2.7 million people in South-Eastern Norway. The Regional Committee for Medical and Health Research Ethics approved the study (approval number 2012/924), which was registered at ClinicalTrials.gov (NCT01721928) November 6, 2012.

\section{Study population}

We included consecutive medical and surgical ICU patients at Oslo University Hospital receiving pharmacological thromboprophylaxis with dalteparin (Fragmin, Pfizer, NJ, USA) between December 2, 2012, and March 2, 2016. Exclusion criteria were age below 18 years, intraocular bleeding, intracranial bleeding, acute spinal cord lesion, inherited coagulopathy, uncontrolled bleeding, therapeutic anticoagulation, uncorrected coagulopathy, pregnancy or postpartum ( $<6$ weeks), participation in an interventional study, chronic kidney disease and anticipated ICU length of stay (LOS) $<48$ hours. All included patients received pharmacological thromboprophylaxis with subcutaneous dalteparin, half had AKI treated with RRT and half had normal kidney function. Standard dose dalteparin was $5000 \mathrm{IU}$ od, but the dose was decreased or increased based on individual risk assessment. The doses were not adjusted due to presence of AKI and RRT. We used mechanical prophylaxis with thigh length graduated compression stockings routinely in the surgical ICU, but not in the medical ICU. RRT was performed using continuous veno-venous haemodialysis with a standard 
prescribed dialysis dose $25-30 \mathrm{ml} / \mathrm{kg} /$ hour and with citrate as regional anticoagulation of the haemodialysis circuit (Multifiltrate, Fresenius Medical Care, Bad Homburg, Germany).

\section{Data collection and study definitions}

Demographic data were collected on age, sex, bodyweight, reason for admission, presence of comorbidities and severity of illness using the Simplified Acute Physiology Score (SAPS) II score. $^{12}$

We diagnosed VTE events as described in detail elsewhere. ${ }^{11}$ This included screening for DVT twice a week using Doppler ultrasound examination of neck, upper and lower extremity veins and computer tomography angiography when clinically indicated. We classified bleeding events according to the Haemorrhage Measurement (HEME) method including data on the site, severity and duration of bleeding. ${ }^{13}$ We collected outcome data on ICU LOS and mortality.

Normal values for coagulation analyses are reported as defined by the reference laboratory, accordingly, target levels for aFXa during dalteparin prophylaxis was set at $\operatorname{trough}<0.10$ $\mathrm{IU} / \mathrm{ml}$ and peak $0.20-0.40 \mathrm{IU} / \mathrm{ml}$.

\section{Biochemical sampling and analyses}

Routine blood samples for the assay of platelet counts, international normalized ratio (INR), activated partial thromboplastin time (APTT) and fibrinogen were collected. We obtained additional blood samples for the purpose of this study short time before (trough level) and 3-4 hours after (peak level) administration of prophylactic subcutaneous dalteparin. We provide a detailed description of the methods used to obtain blood samples and analyse coagulation tests (AT, PC, aFXa, TEG, CAT and MPs) in Appendix S1. 


\section{Statistical methods}

Data are presented as number (percentage), median (interquartile range (IQR)) or mean (standard deviation (SD)). We performed univariate analyses of categorical data using the Pearson's Chi square test, and Fisher's exact test when appropriate. We compared continuous variables using the Mann-Whitney U test for skewed data, or independent sample t-test for normally distributed data. We evaluated discrimination by analyses of the area under receiver operating characteristics curve (AuROC), acceptable discriminating capability was defined as an AuROC above 0.7 . We conducted a linear regression analysis to assess a possible association between the administrated dalteparin dose and peak coagulation analyses and evaluate the property of correlation. In the analyses of microparticles procoagulant activity (MPa) and tissue factor-bearing microparticles procoagulant activity (MP-TFa) levels below lowest detection range $(<1.3)$ were set as 1.2 in the calculations. We handled missing data by using only available data. We did not perform a statistical power analysis since the coagulation analysis was not the primary outcome of the NORIDES study. Statistical analyses were performed using SPSS 23 for Windows (Armonk, NY, USA: IBMCorp), two-sided pvalues less than 0.05 were considered statistically significant. 


\section{Results}

\section{Patient characteristics}

Of 75 patients included in the NORIDES study, ${ }^{11} 25$ were excluded from this sub-study due to presence of VTE on admission $(n=11)$, ICU LOS $<48$ hours $(n=5)$ or blood samples not collected for coagulation analyses $(n=9)$ (Figure 1$)$.

Among the 50 included ICU patients (76\% males, mean age 62 years), $36(72 \%)$ and 14 (28\%) had surgical and medical reason for admission, respectively. Half of the patients had severe AKI undergoing RRT and half had normal kidney function. The patients were severely ill with a mean SAPS II score of 43, median ICU LOS 11 days, and ICU mortality in nine (18\%) of the patients (Table 1). There was no loss to follow-up.

\section{Use of thromboprophylaxis}

All patients received prophylactic dalteparin administrated once daily, the dose at the day of blood sample analysis was mean $5600( \pm 1562)$ IU or $70.5( \pm 18.5) \mathrm{IU} / \mathrm{kg}$ (Table 1).

Mechanical thromboprophylaxis with graduated compression stockings was used in 45 (90\%) of the patients.

\section{VTE and bleeding events}

During ICU stay, VTE was observed in five (10\%) of the patients; they all had asymptomatic DVT and none had PE. Bleeding according to the HEME tool was observed in $21(42 \%)$ of the patients, $13(26 \%)$ with minor and eight (16\%) with major bleeding (Table 1). None of the VTE or bleeding events were fatal or resulted in long-time sequelae. 


\section{Coagulation analyses in all patients}

Routine coagulation tests revealed that all patients had platelet counts $171(94-271) \cdot 10^{9}$ cells/1, INR 1.15 (1.10-1.28), APTT 42 (38-46) seconds and fibrinogen 5.7 (3.6-6.9) g/l. Trough coagulation testes were AT 82.0 (71.7-99.4) \%, PC 77.8 (56.9-106.4) \% and d-dimer 7.7 (3.1-13.0) mg/ml (Table 1).

Median peak aFXa level was $0.21(0.13-0.29) \mathrm{IU} / \mathrm{ml}$, and the number of patients below, within and above prophylactic target were $21(42 \%), 25(50 \%)$ and four (8\%), respectively. There was a correlation between administered dalteparin dose per kilogram bodyweight and peak aFXa $(\mathrm{r}=0.32, \mathrm{p}=0.02)$. This could be mathematically expressed as peak $\mathrm{aFXa}=[0.003 \mathrm{x}$ dalteparin dose $(\mathrm{IU} / \mathrm{kg})]+0.049$. Based on this, we calculated the dalteparin doses needed to achieve prophylactic peak aFXa range for different bodyweights. A target peak aFXa set at $0.30 \mathrm{IU} / \mathrm{ml}$ would imply a dalteparin dose of around $5000 \mathrm{IU}$ od for a $60 \mathrm{~kg}$ person and 7500 IU od for a $90 \mathrm{~kg}$ person (Figure 2). There was no correlation between administered dalteparin dose per kilogram bodyweight and peak TEG native reaction time (r) (Appendix S2) or peak CAT normalised endogenous thrombin potential (nETP) (Appendix S3). We were unable to calculate correlation for MPs since data could not be transformed to normal distribution. Median trough aFXa levels was $0.03(0.02-0.05), 48(96 \%)$ patients were within target and two (4\%) were above target.

\section{Coagulation analyses in patients with venous thromboembolism}

Coagulation analyses were similar in patients with and without VTE, except that peak MPs were higher in patients with VTE compared to those without VTE (Table 1). The coagulation analysis with best discriminating power for VTE was trough d-dimer (AuROC 0.77 (95\% CI $0.52-1.00), p=0.05)$, levels with and without VTE were $23.4 \mathrm{vs} 5.9 \mathrm{mg} / \mathrm{ml}(\mathrm{p}=0.05)$ (Figure 
3). Patients with and without VTE had similar peak ( 0.18 vs $0.21 \mathrm{IU} / 1, \mathrm{p}=0.72$ ) and trough (0.03 vs $0.03 \mathrm{IU} / \mathrm{ml}, \mathrm{p}=0.40)$ aFXa levels (Table 1$)$, and proportion of patients within prophylactic peak aFXa range (40 vs 51\%, p=0.64) (Figure 4).

\section{Coagulation analyses in patients with major bleeding}

Patients with major bleeding had lower AT levels, trough MPa levels and several peak CAT parameters compared to those without major bleeding (Appendix S4). The coagulation analysis with best discriminating power for major bleeding was peak CAT normalized peak thrombin (AuROC 0.81 (95\% CI 0.64-0.98), p=0.01), levels with and without major bleeding were 50.7 vs $18.3 \%(p=0.01)$ (Figure 3). Patients with and without major bleeding had similar peak (0.22 vs $0.21 \mathrm{IU} / 1, \mathrm{p}=0.38)$ and trough $(0.03 \mathrm{vs} 0.04 \mathrm{IU} / \mathrm{ml}, \mathrm{p}=0.12)$ aFXa levels (Additional file 4), and proportion of patients within prophylactic peak aFXa range (48 vs $63 \%, \mathrm{p}=0.44)$ (Figure 4).

\section{Coagulation analyses in patients with severe acute kidney injury}

Patients with AKI and RRT had lower platelet counts, higher INR, lower AT levels, lower trough CAT parameters and lower peak TEG native thombodynamic potential index (TPI) compared to those without AKI and RRT. Patients with and without AKI and RRT had similar peak ( 0.18 vs. $0.24, \mathrm{p}=0.13)$ and trough $(0.03$ vs. $0.04, \mathrm{p}=0.47)$ aFXa levels (Appendix S5) and occurrence of VTE and major bleeding (Table 1, Additional file 4).

\section{Coagulation analyses in patients with variable dalteparin dose}

Patients with dalteparin dose 5000 IU od had lower trough TEG native maximum amplitude (MA), higher trough CAT normalized activated protein C sensitivity ratio (nAPC-SR) and longer trough CAT normalized lag time (nLagtime) compared to those receiving 7500 IU od. 
Patients receiving dalteparin $5000 \mathrm{IU}$ od, compared to $7500 \mathrm{IU}$ od, had lower peak aFXa levels $(0.19$ vs $0.30 \mathrm{IU} / \mathrm{ml}, \mathrm{p}<0.01)$, proportion of patients within prophylactic peak aFXa range (39 vs $82 \%, \mathrm{p}=0.01$ ) (Figure 4), but similar through aFXa levels $(0.04 \mathrm{vs} 0.03 \mathrm{IU} / \mathrm{ml}$, $\mathrm{p}=0.37)($ Appendix S6). 


\section{Discussion}

In this prospective observational study of 50 ICU patients receiving thromboprophylaxis with dalteparin, 10\% had VTE and 16\% major bleeding during their ICU stay. Dalteparin efficiency assessed by peak aFXa levels revealed that only half of patients were within prophylactic range. There was a correlation between administered dalteparin dose and peak aFXa levels. Use of dalteparin prophylaxis seemed safe since through aFXa levels were below target limit in $96 \%$ of the patients, and none of the patients had bleeding that was fatal or resulted in long-time sequelae. Presence of VTE, major bleeding or AKI treated with RRT did not affect peak or through aFXa levels.

In the present study, we observed that $10 \%$ of patients developed VTE and $21 \%$ had major bleeding despite use of thromboprophylaxis, comparable to reports from other ICU patients. ${ }^{14}$ Some data indicate that the pharmacological effect of LMWH is reduced in certain patient groups, for instance high bodyweight. ${ }^{15,16}$ Peak coagulation analyses to assess efficacy is therefore proposed, and aFXa measurements have been used in such an extent that prophylactic ranges are defined. ${ }^{17}$ Peak aFXa levels were in the present study correlated to administered dalteparin dose, but not peak TEG or CAT parameters, indicating that aFXa seem to be the best biomarker of LMWH prophylaxis efficiency. According to current guidelines monitoring is not recommended for most patients, but if required aFXa is the recommended test. ${ }^{10,18}$

We observed that half of our patients were within prophylactic peak aFXa range, similar observations has been found in other ICU patients. ${ }^{19-21}$ Our data suggest that increased dalteparin dose may be beneficial; a practical solution might be that patients weighting less than $90 \mathrm{~kg}$ should receive $5000 \mathrm{IU}$ od and those above $90 \mathrm{~kg} 7500 \mathrm{IU}$ od. Current guidelines recommend fixed or weight-adjusted doses for LMWH thromboprophylaxis, and that aFXa 
measurement may be used in obese patients. ${ }^{10}$ However, two studies in ICU patients revealed that increased prophylactic LMWH dose did not lead to less VTE events. ${ }^{22,23}$ Although some studies reported that high aFXa levels were associated with increased bleeding risk, ${ }^{24,25}$ several other studies failed to show a relationship between aFXa levels and bleeding. ${ }^{26,27}$

The safety of LMWH prophylaxis is a concern especially in patients with reduced drug elimination, for instance reduced kidney function. ${ }^{10,28}$ Trough aFXa levels has therefore been proposed as a biomarker of LMWH safety. ${ }^{17}$ The present study revealed that only $4 \%$ had trough levels above prophylactic range, indicating that drug accumulation is unlikely to occur even in severe AKI patients. In two other studies among ICU patients with AKI receiving dalteparin prophylaxis, there was no evidence of drug accumulation or increased bleeding..$^{28,}$ ${ }^{29}$ Current guidelines give no clear recommendation for prophylactic dosing in patients with AKI and RRT due to limited data on the many available LMWHs. ${ }^{10}$

Patients with and without VTE had similar aFXa measurements and proportion of patients within prophylactic peak aFXa range. This is interesting, since three interventional studies of dose adjustments based on coagulation analyses revealed similar occurrence of VTE in two of the studies. ${ }^{30-32}$ In the present study, peak MPs were higher in patients with VTE compared to without VTE, but the utility of results is limited because a large proportion of patients had levels below lower detection range. The biomarker with the best discriminating power for VTE was trough d-dimer, but both patients with and without VTE had high levels. Previous studies of d-dimer as a biomarker of VTE in ICU patients have shown conflicting results. ${ }^{33-35}$ In contrast to a recent study, we found that patients with and without VTE had similar native TEG MA. ${ }^{36}$

In our study, patients with and without major bleeding had had similar aFXa measurements and proportion of patients within prophylactic aFXa range. A recent systematic review 
revealed that aFXa levels were not correlated to bleeding in ICU patients receiving LMWH prophylaxis. ${ }^{37}$ An interesting finding was that patients with major bleeding had lower AT, trough MPa and peak nETP levels than those without bleeding. The coagulation analyses with best discriminating power for major bleeding was peak CAT normalized peak thrombin, and this biomarker may be useful in ICU patients to detect bleeding tendency.

Patients with and without AKI and RRT had similar aFXa measurements and proportion of patients within prophylactic aFXa range. This is useful information because it remains uncertain to what extent presence of AKI and treatment with RRT affects LMWH prophylaxis. ${ }^{10}$ We also registered that patients with and without AKI and RRT had similar rates of VTE and major bleeding in the present study, although former studies have revealed that AKI patients may have increased bleeding risk. ${ }^{38,39}$

The present study has limitations as we present observational data from selected patients in a single centre study that might have limited external validity. Our small sample size and lack of statistical power analysis imply that the results should be interpreted with caution.

Moreover, the clinical importance of asymptomatic DVT is under debate. Bleeding events observed in this study may differ from what is considered clinically important bleedings. The bleeding incidences would probably be altered with use of other bleeding assessment tools such as for instance the World Health Organisation (WHO) bleeding scale. When using coagulation analyses correct sampling is challenging, and there is no consensus on target levels in an ICU setting. ${ }^{40}$ Due to technical difficulties, we have some missing data regarding the coagulation analyses. Utility of MP measurements was restricted since many observations were below lower detection range. Finally, coagulation biomarkers certainly have limitations in detecting VTE and bleeding events, and it remains uncertain how peak and trough levels are associated with thrombosis and bleeding. 
Strengths of the study are that we compared patients from the same cohort and time period with no loss to follow-up. We used several coagulation analyses and provided both trough and peak levels for most biomarkers. Due to dilution of samples, we were able to show that ddimer may be a useful biomarker of VTE in the ICU. Finally, our study design made it possible to compare coagulation analyses in patients with and without VTE, major bleeding, AKI and RRT and variable dalteparin doses.

The implications of this study for clinical practice is limited. Future research should evaluate d-dimer as a biomarker of VTE and peak CAT normalized peak thrombin as a biomarker of bleeding. More research is warranted in order to give recommendations for aFXa measurements in ICU patients receiving thromboprophylaxis.

In conclusion, this observational study of ICU patients receiving thromboprophylaxis with dalteparin revealed that trough aFXa levels were low indicating no drug accumulation. Peak aFXa was the best biomarker of LMHW efficiency, but only half of patients were within prophylactic range. Increased LMWH doses may be an option to increase thromboprophylaxis efficiency since administered dalteparin dose affected the peak aFXa levels and proportion of patients within target range. Presence of VTE, major bleeding or AKI treated with RRT did not influence aFXa measurements.

\section{Acknowledgement}

This study was financially supported by departmental funding only. The authors declare that they have no conflict of interest in relation to this manuscript. 


\section{Appendices}

\section{Appendix S1}

Detailed description of the methods used to collect and analyse coagulation tests.

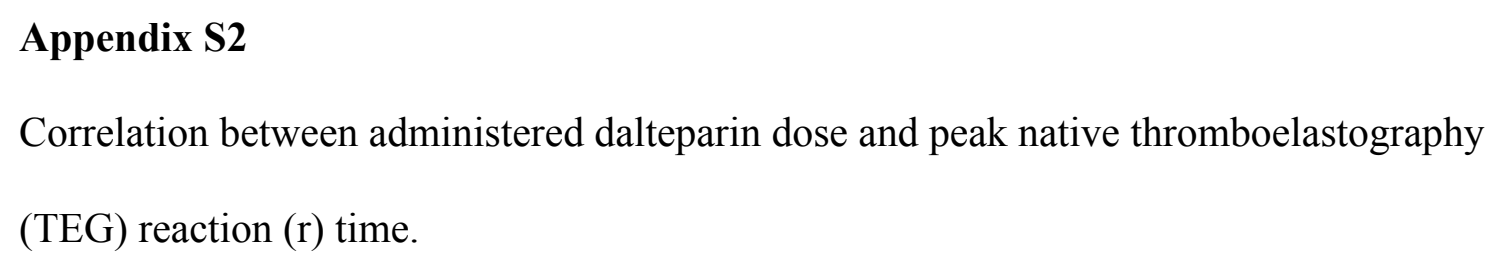

\section{Appendix S3}

Correlation between administered dalteparin dose and peak normalized endogenous thrombin potential at the calibrated automated thrombogram.

\section{Appendix S4}

Table comparing results of coagulation analyses in patients with and without major bleeding.

\section{Appendix S5}

Table comparing results of coagulation analyses in patients with and without acute kidney injury treated with renal replacement therapy.

\section{Appendix S6}

Table comparing results of coagulation analyses in patients with variable dalteparin dose. 


\section{Figure legends}

\section{Figure 1}

Flowchart of the study. Abbreviations: ICU: intensive care unit, VTE: venous thromboembolism, LOS: length of stay.

\section{Figure 2}

Correlation between administered dalteparin dose (IU/kg) and peak anti-factor X activity (aFXa) levels $(\mathrm{IU} / \mathrm{ml})$ in intensive care unit patients receiving dalteparin prophylaxis. Data are presented as scatter diagram with correlation line and compared using linear regression analysis.

\section{Figure 3}

Coagulation analyses related to clinical parameters in intensive care unit patients receiving dalteparin prophylaxis. Data are presented as box plots and receiving operator characteristics (ROC) curves and compared using Mann-Whitney U test. Abbreviations: VTE: venous thromboembolism, CAT: calibrated automated thrombogram, nPeak: normalized peak thrombin, AKI: acute kidney injury, RRT: renal replacement therapy.

\section{Figure 4}

Peak anti-factor X activity (aFXa) analyses related to clinical parameters in intensive care unit patients receiving dalteparin prophylaxis. Data are presented as box plots and bar charts and compared using Mann-Whitney U and Pearson's Chi square test tests. Abbreviation: VTE: venous thromboembolism. 


\section{References}

1. Holbrook A, Schulman S, Witt DM, et al. Evidence-based management of anticoagulant therapy: Antithrombotic Therapy and Prevention of Thrombosis, 9th ed: American College of Chest Physicians Evidence-Based Clinical Practice Guidelines. Chest. 2012,141:e152S-e184s.

2. Cook D, Crowther M, Meade M, et al. Deep venous thrombosis in medical-surgical critically ill patients: prevalence, incidence, and risk factors. Critical care medicine. 2005,33:1565-1571.

3. Kahn SR, Lim W, Dunn AS, et al. Prevention of VTE in nonsurgical patients: Antithrombotic Therapy and Prevention of Thrombosis, 9th ed: American College of Chest Physicians Evidence-Based Clinical Practice Guidelines. Chest. 2012,141:e195S-e226S.

4. Cook D, Meade M, Guyatt G, et al. Dalteparin versus unfractionated heparin in critically ill patients. N Engl J Med. 2011,364:1305-1314.

5. Minet C, Potton L, Bonadona A, et al. Venous thromboembolism in the ICU: main characteristics, diagnosis and thromboprophylaxis. Crit Care. 2015,19:287.

6. Ribic C, Lim W, Cook D, Crowther M. Low-molecular-weight heparin thromboprophylaxis in medical-surgical critically ill patients: a systematic review. Journal of critical care. 2009,24:197-205.

7. Vahtera A, Vaara S, Pettila V, Kuitunen A. Plasma anti-FXa level as a surrogate marker of the adequacy of thromboprophylaxis in critically ill patients: A systematic review. Thrombosis research. 2016,139:10-16.

8. Van PY, Cho SD, Underwood SJ, Morris MS, Watters JM, Schreiber MA. Thrombelastography versus Anti-factor Xa levels in the assessment of prophylacticdose enoxaparin in critically ill patients. The Journal of trauma. 2009,66:1509-1515.

9. White H, Sosnowski K, Bird R, Jones M, Solano C: The utility of thromboelastography in monitoring low molecular weight heparin therapy in the coronary care unit. Blood coagulation \& fibrinolysis : an international journal in haemostasis and thrombosis 2012,23:304-310.

10. Garcia DA, Baglin TP, Weitz JI, Samama MM. Parenteral anticoagulants: Antithrombotic Therapy and Prevention of Thrombosis, 9th ed: American College of Chest Physicians Evidence-Based Clinical Practice Guidelines. Chest. 2012,141:e24Se43S.

11. Beitland S, Wimmer H, Lorentsen T, et al. Venous thromboembolism in the critically ill: A prospective observational study of occurrence, risk factors and outcome. Acta Anaesthesiol Scand. 2019,63:630-638.

12. Le Gall JR, Lemeshow S, Saulnier F. A new Simplified Acute Physiology Score (SAPS II) based on a European/North American multicenter study. Jama. 1993,270:2957-2963.

13. Arnold DM, Donahoe L, Clarke FJ, et al. Bleeding during critical illness: a prospective cohort study using a new measurement tool. Clinical and investigative medicine Medecine clinique et experimentale. 2007,30:E93-102.

14. Ribic C, Lim W, Cook D, Crowther M. Low-molecular-weight heparin thromboprophylaxis in medical-surgical critically ill patients: a systematic review. $J$ Crit Care. 2009,24:197-205.

15. Mayr AJ, Dunser M, Jochberger S, et al. Anti-factor Xa activity in intensive care patients receiving thromboembolic prophylaxis with standard doses of enoxaparin. Thromb Res. 2002,105:201-204. 
16. Borkgren-Okonek MJ, Hart RW, et al. Enoxaparin thromboprophylaxis in gastric bypass patients: extended duration, dose stratification, and anti-factor Xa activity. Surg Obes Relat Dis. 2008,4:625-631.

17. Wei MY, Ward SM. The Anti-factor Xa Range For Low Molecular Weight Heparin Thromboprophylaxis. Hematol Rep. 2015,7:5844.

18. Laposata M, Green D, Van Cott EM, Barrowcliffe TW, Goodnight SH, Sosolik RC. College of American Pathologists Conference XXXI on laboratory monitoring of anticoagulant therapy: the clinical use and laboratory monitoring of low-molecularweight heparin, danaparoid, hirudin and related compounds, and argatroban. Arch Pathol Lab Med. 1998;122:799-807.

19. Cheng SS, Nordenholz K, Matero D, et al. Standard subcutaneous dosing of unfractionated heparin for venous thromboembolism prophylaxis in surgical ICU patients leads to subtherapeutic factor Xa inhibition. Intensive Care Med. 2012,38:642-648.

20. Pannucci CJ, Prazak AM, Scheefer M. Utility of anti-factor Xa monitoring in surgical patients receiving prophylactic doses of enoxaparin for venous thromboembolism prophylaxis. Am J Surg. 2017,213:1143-1152.

21. Walker CK, Sandmann EA, Horyna TJ, Gales MA. Increased Enoxaparin Dosing for Venous Thromboembolism Prophylaxis in General Trauma Patients. Ann Pharmacother. 2017,51:323-331.

22. Hebbeler SL, Marciniak CM, Crandall S, Chen D, Nussbaum S, Mendelewski S. Daily vs twice daily enoxaparin in the prevention of venous thromboembolic disorders during rehabilitation following acute spinal cord injury. J Spinal Cord Med. 2004;27:236-240.

23. Bush S, LeClaire A, Hampp C, Lottenberg L. Review of a large clinical series: onceversus twice-daily enoxaparin for venous thromboembolism prophylaxis in high-risk trauma patients. $J$ Intensive Care Med. 2011,26:111-115.

24. Levine M, Hirsh J, Kelton J. Heparin-induced bleeding. In: Land DA, Lindahl U, editors. Heparin: Chemical and Biological Properties, Clinical Applications. London, England. Edward Arnold; 1989. p.517-532.

25. Bates SM, Greer IA, Middeldorp S, Veenstra D, Prabulos A-M, Vandvik PO. VTE, thrombophilia, antithrombotic therapy, and pregnancy: antithrombotic therapy and prevention of thrombosis, 9th ed: American College of Chest Physicians evidencebased clinical practice guidelines. Chest. 2012;141:e691S-e736S.

26. Bara L, Leizorovicz A, Picolet H, Samama M. Correlation between anti-Xa and occurrence of thrombosis and haemorrhage in postsurgical patients treated with either Logiparin or unfractionated heparin. Thromb Res. 1992;65:641-650.

27. Walenga JM, Hoppensteadt D, Fareed J. Laboratory monitoring of the clinical effects of low molecular weight heparins. Thromb Res. 1991;14:49-62.

28. Rabbat CG, Cook DJ, Crowther et al. Dalteparin thromboprophylaxis for critically ill medical-surgical patients with renal insufficiency. J Crit Care. 2005,20:357-363.

29. Douketis J, Cook D, Meade M, et al. Prophylaxis against deep vein thrombosis in critically ill patients with severe renal insufficiency with the low-molecular-weight heparin dalteparin: an assessment of safety and pharmacodynamics: the DIRECT study. Arch Intern Med. 2008;168:1805-1812.

30. Connelly CR, Van PY, Hart KD, et al. Thrombelastography-Based Dosing of Enoxaparin for Thromboprophylaxis in Trauma and Surgical Patients: A Randomized Clinical Trial. JAMA Surg. 2016;151:e162069. 
31. Singer GA, Riggi G, Karcutskie CA, et al. Anti-Xa-guided enoxaparin thromboprophylaxis reduces rate of deep venous thromboembolism in high-risk trauma patients. J Trauma Acute Care Surg. 2016;81:1101-1108.

32. Ko A, Harada MY, Barmparas G, et al. Association between enoxaparin dosage adjusted by anti-Factor Xa trough level and clinically evident venous thromboembolism after trauma. JAMA Surg. 2016;151:1006-1013.

33. Lawall H, Oberacker R, Zemmrich C, Bramlage P, Diehm C, Schellong SM. Prevalence of deep vein thrombosis in acutely admitted ambulatory non-surgical intensive care unit patients. BMC Res Notes. 2014;7:431.

34. Rogers F, Rebuck JA, Sing RF. Venous thromboembolism in trauma: an update for the intensive care unit practitioner. J Intensive Care Med. 2007;22:26-37.

35. Crowther MA, Cook DJ, Griffith LE, et al. Neither baseline tests of molecular hypercoagulability nor D-dimer levels predict deep venous thrombosis in critically ill medical-surgical patients. Intensive Care Med. 2005;31:48-55.

36. Harahsheh Y, Duff OC, Ho KM. Thromboelastography predicts thromboembolism in critically ill coagulopathic patients. Crit Care Med. 2019;47:826-832.

37. Vahtera A, Vaara S, Pettilä V, Kuitunen A. Plasma anti-FXa level as a surrogate marker of the adequacy of thromboprophylaxis in critically ill patients: A systematic review. Thromb Res. 2016;139:10-16.

38. Al-Dorzi HM, Al-Heijan A, Tamim HM, et al. Renal failure as a risk factor for venous thromboembolism in critically Ill patients: a cohort study. Thromb Res. 2013;132:671-675.

39. Elapavaluru S, Kellum JA. Why do patients die of acute kidney injury? Acta Clin Belg. 2007;62:326-331.

40. van Bergen EDP, Huisman A, Welsing PM, et al. Dalteparin and anti-Xa: a complex interplay of therapeutic drug monitoring. Neth J Med. 2019;77:360-365. 
ICU patients with prophylactic dalteparin assessed for bleeding and thrombosis $(n=75)$

Patients without VTE at admission with ICU LOS $>48$ hours $(n=59)$

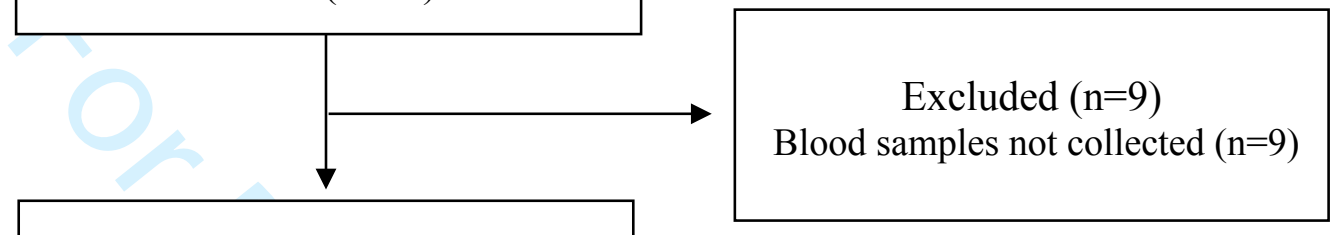

Studied ICU patients with blood samples collected for coagulation analyses $(n=50)$
Not included $(\mathrm{n}=16)$

VTE at admission $(\mathrm{n}=11)$ ICU LOS $<48$ hours $(n=5)$

\section{Excluded $(\mathrm{n}=9)$}

Blood samples not collected $(n=9)$ 


\section{Correlation between administered dalteparin dose and peak anti-factor Xa levels}

Scatter plot of administrated dalteparin dose (IU/kg bodyweight) and peak anti-factor X activity (aFXa) $(\mathrm{IU} / \mathrm{ml})(\mathbf{n}=\mathbf{5 0})$

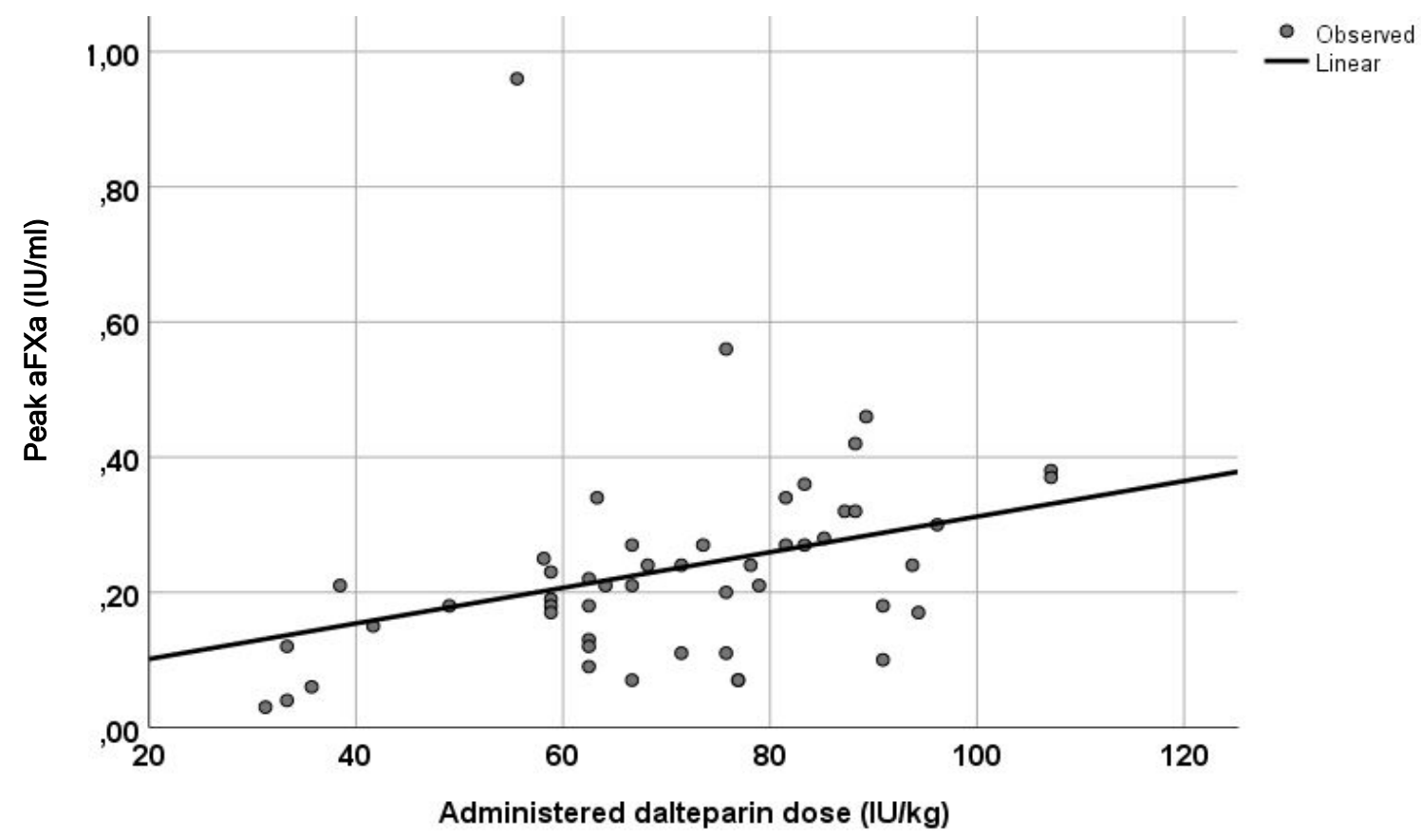

Variables were significantly correlated, $\mathrm{r}=0.318, \mathrm{p}=0.024$. Peak aFXa $=(0.003 \mathrm{x} \mathrm{IU} / \mathrm{kg}$ dalteparin $)+0.049$

Calculation of administered dalteparin dose needed to achieve prophylactic levels of peak aFXa (IU/ml)

\begin{tabular}{c|c|c|c}
\hline Patient bodyweight & Target peak aFXa $=0.20$ & Target peak aFXa $=0.30$ & Target peak aFXa $=0.40$ \\
\hline $50 \mathrm{~kg}$ & $2517 \mathrm{IU} \times 1$ dalteparin & $4183 \mathrm{IU} \times 1$ dalteparin & $5850 \mathrm{IU} \times 1$ dalteparin \\
$60 \mathrm{~kg}$ & $3020 \mathrm{IU} \times 1$ dalteparin & $5020 \mathrm{IU} \times 1$ dalteparin & $7020 \mathrm{IU} \times 1$ dalteparin \\
$70 \mathrm{~kg}$ & $3523 \mathrm{IU} \times 1$ dalteparin & $5857 \mathrm{IU} \times 1$ dalteparin & $8190 \mathrm{IU} \times 1$ dalteparin \\
$80 \mathrm{~kg}$ & $4027 \mathrm{IU} \times 1$ dalteparin & $6693 \mathrm{IU} \times 1$ dalteparin & $9360 \mathrm{IU} \times 1$ dalteparin \\
$90 \mathrm{~kg}$ & $4530 \mathrm{IU} \times 1$ dalteparin & $7530 \mathrm{IU} \times 1$ dalteparin & $10530 \mathrm{IU} \times 1$ dalteparin \\
$100 \mathrm{~kg}$ & $5033 \mathrm{IU} \times 1$ dalteparin & $8367 \mathrm{IU} \times 1$ dalteparin & $11700 \mathrm{IU} \times 1$ dalteparin \\
\hline
\end{tabular}




\section{Coagulation analyses in intensive care unit patients receiving dalteparin prophylaxis}

Patients with and without venous thromboembolism: Trough d-dimer (mg/ml)
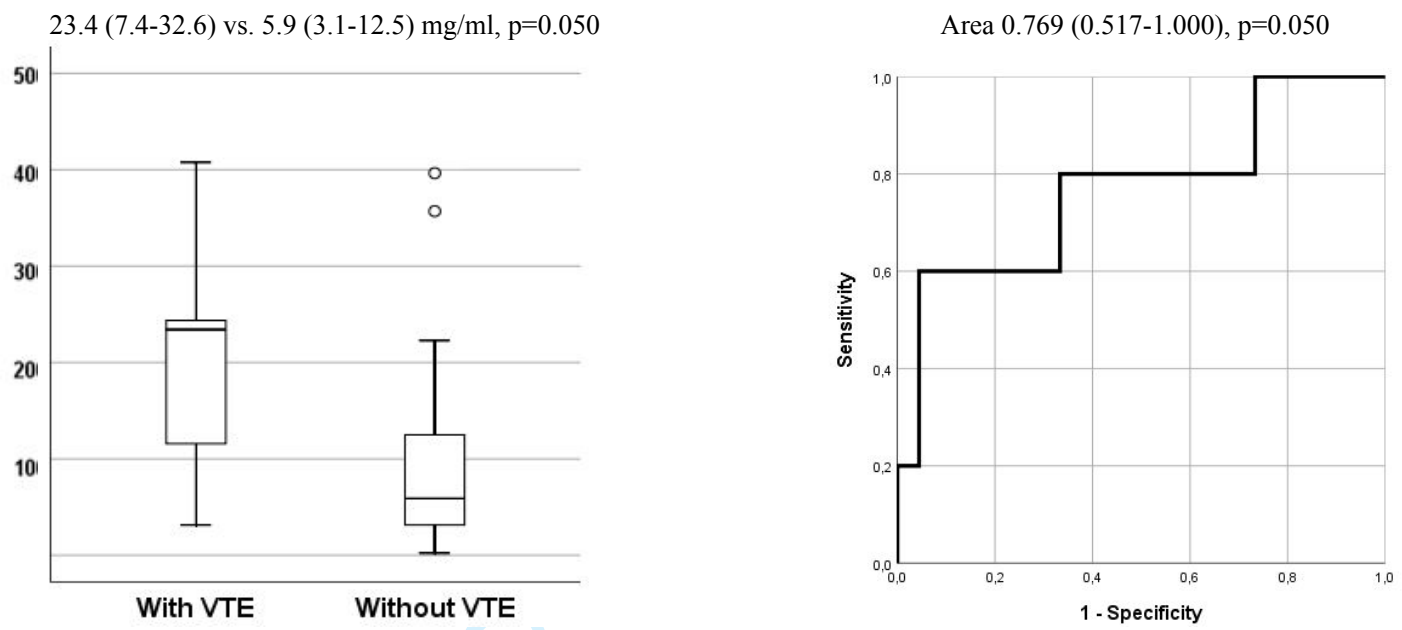

Patients with and without major bleeding: Peak CAT nPeak (\%)
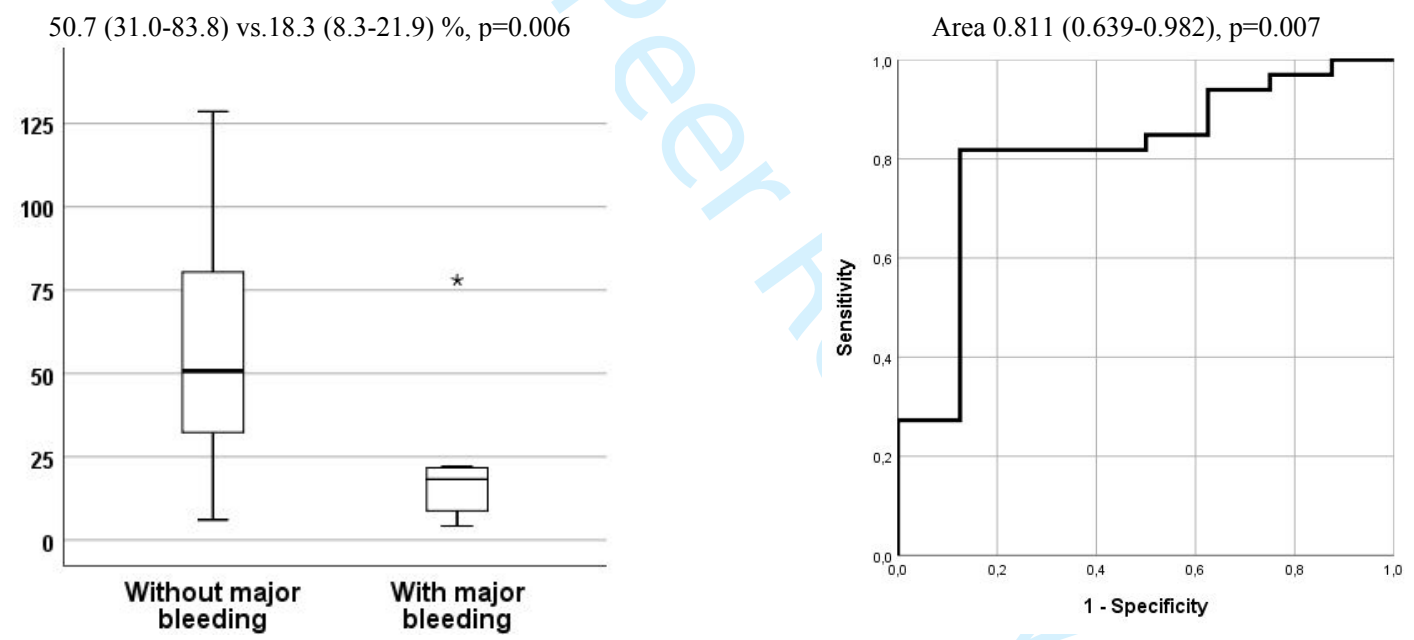

Patients with and without acute kidney injury with renal replacement therapy: Routine platelets
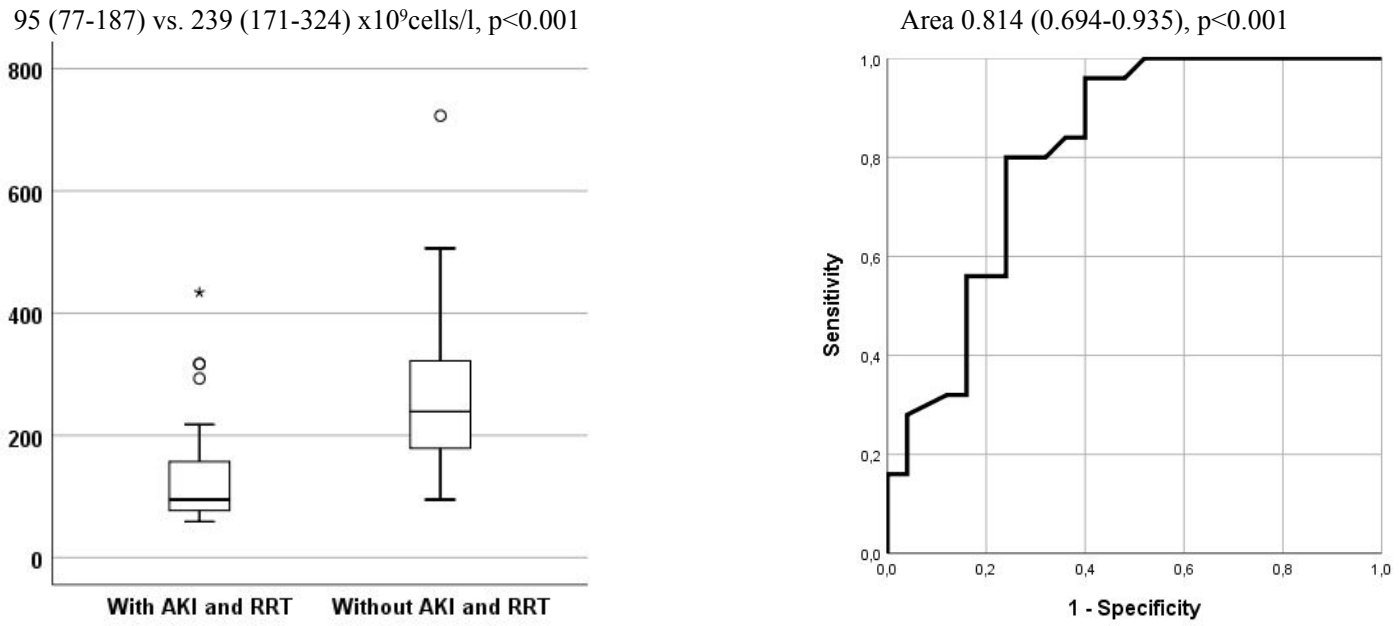
Peak anti-factor Xa analyses in intensive care patients receiving prophylactic dalteparin

\section{Patients with $(n=5)$ and without $(n=45)$ venous thromboembolism}

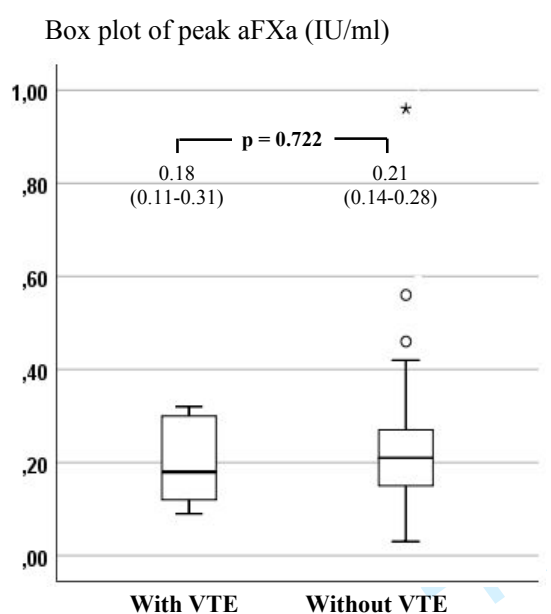

Bar chart of patients within prophylactic range (n (\%))

Patients without $(n=42)$ and with $(n=8)$ major bleeding

Box plot of peak aFXa (IU/ml)

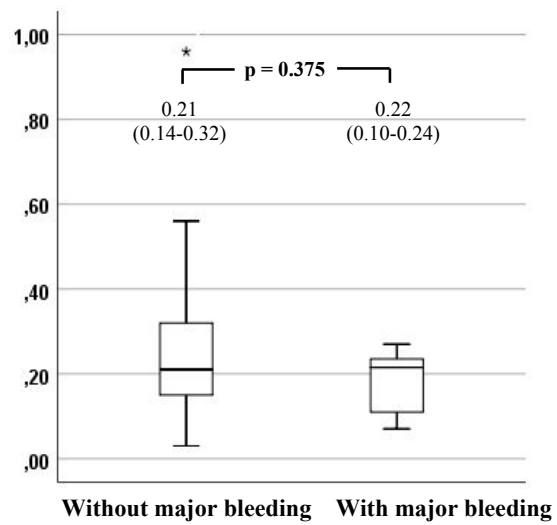

Bar chart of patients within prophylactic range (n (\%))

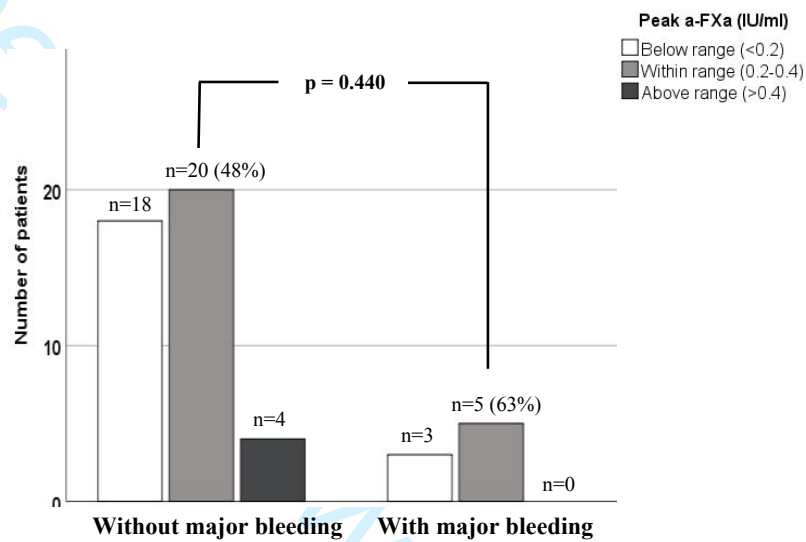

Patients with dalteparin dose 5000 IUx1 $(n=28)$ and 7500 IEx1 (n=17)

Box plot of peak aFXa (IU/ml)

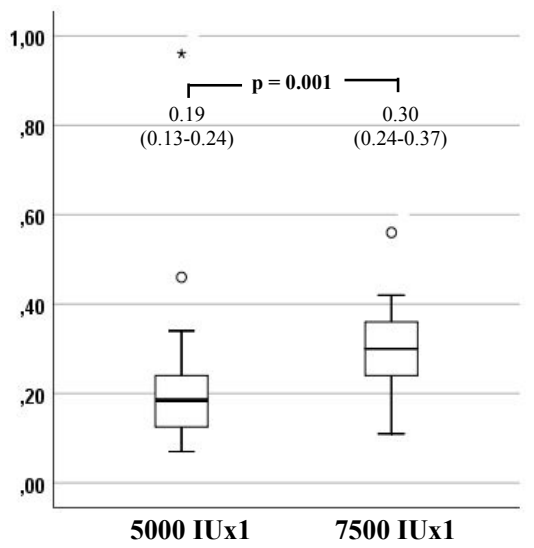

Bar chart of patients within prophylactic range (n (\%))

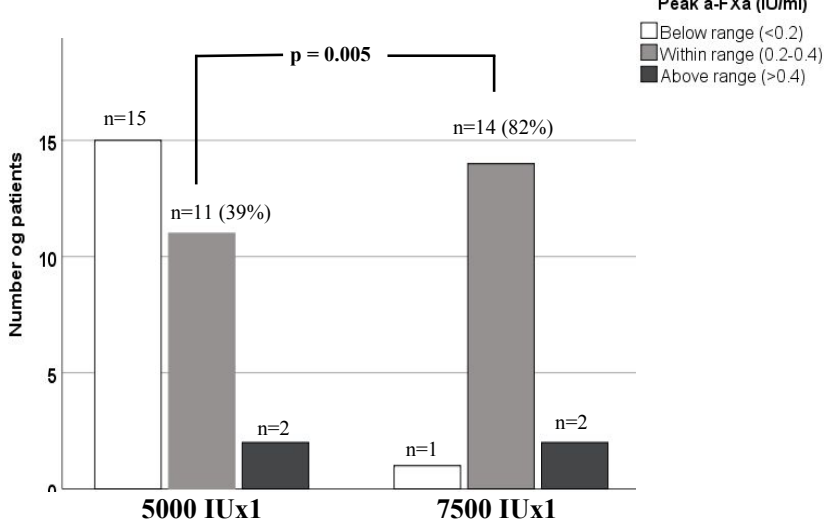


Table 1: Coagulation analyses in intensive care unit patients with and without VTE

\begin{tabular}{|c|c|c|c|c|}
\hline Patient data & $\begin{array}{c}\text { All included } \\
\text { patients } \\
(n=50)\end{array}$ & $\begin{array}{c}\text { Patients } \\
\text { with VTE } \\
(n=5)\end{array}$ & $\begin{array}{c}\text { Patients } \\
\text { without VTE } \\
(n=45)\end{array}$ & $\begin{array}{c}\text { p- } \\
\text { value }\end{array}$ \\
\hline Age, years & $62.0( \pm 11.6)$ & $65.0( \pm 14.2)$ & $61.6( \pm 11.5)$ & 0.546 \\
\hline Male sex & $38(76.0)$ & $4(80.0)$ & $34(75.6)$ & 1.000 \\
\hline BMI, kilogram/square meters & $24.6( \pm 3.6)$ & $25.0( \pm 2.4)$ & $24.6( \pm 3.7)$ & 0.824 \\
\hline Surgical admission & $36(72.0)$ & $3(60.0)$ & $33(73.3)$ & 0.611 \\
\hline Any comorbidity & $36(72.0)$ & $4(80.0)$ & $32(71.1)$ & 1.000 \\
\hline Dalteparin dose, IU (blood sample day) & $5600( \pm 1562)$ & $6000( \pm 1369)$ & $5556( \pm 1589)$ & 0.551 \\
\hline Dalteparin dose, IU/kg (blood sample day) & $70.5( \pm 18.5)$ & $73.6( \pm 17.2)$ & $70.1( \pm 18.8)$ & 0.690 \\
\hline SAPS II, score & $43.2( \pm 16.7)$ & $48.2( \pm 14.2)$ & $42.7( \pm 17.0)$ & 0.490 \\
\hline $\mathrm{AKI}$ and RRT & $25(50.0)$ & $1(20.0)$ & $24(53.3)$ & 0.240 \\
\hline Any bleeding & $21(42.0)$ & $4(80.0)$ & $17(37.8)$ & 0.148 \\
\hline Major bleeding & $8(16.0)$ & $1(20.0)$ & $7(15.6)$ & 1.000 \\
\hline ICU LOS & $11.0(7.8-20.0)$ & $22.0(17.0-68.5)$ & $11.0(7.0-16.5)$ & 0.011 \\
\hline ICU mortality & $9(18.0)$ & $0(0.0)$ & $9(20.0)$ & 0.570 \\
\hline \multicolumn{5}{|l|}{ Conventional coagulation tests } \\
\hline Routine platelets $\left(\mathrm{x} 10^{9}\right.$ cells/l)(n=50) & $171(94-271)$ & $147(92-329)$ & $179(94-279)$ & 0.897 \\
\hline Routine INR $(\mathrm{n}=40)$ & $1.15(1.10-1.28)$ & $1.20(1.13-1.43)$ & $1.10(1.10-1.28)$ & 0.330 \\
\hline Routine APTT (seconds) $(\mathrm{n}=25)$ & $42(38-46)$ & $22.5(4.0-n . a)$ & $42(38-46)$ & 0.145 \\
\hline Routine fibrinogen $(\mathrm{g} / \mathrm{l})(\mathrm{n}=23)$ & $5.7(3.6-6.9)$ & 3.4 (3.3-n.a.) & $6.0(3.9-7.0)$ & 0.102 \\
\hline \multicolumn{5}{|l|}{ Trough coagulation tests } \\
\hline Antithrombin $(\%)(\mathrm{n}=50)$ & $82.0(71.7-99.4)$ & $78.8(64.3-84.8)$ & $82.4(72.4-101.3)$ & 0.357 \\
\hline Protein C $(\%)(\mathrm{n}=50)$ & $77.8(56.9-106.4)$ & $73.7(61.5-100.0)$ & $80.5(56.7-107.2)$ & 0.910 \\
\hline $\mathrm{aFXa}(\mathrm{IU} / \mathrm{ml})(\mathrm{n}=50)$ & $0.03(0.02-0.05)$ & $0.03(0.02-0.04)$ & $0.03(0.02-0.05)$ & 0.404 \\
\hline $\mathrm{D}-\operatorname{Dimer}(\mu \mathrm{g} / \mathrm{ml})(\mathrm{n}=50)$ & $7.7(3.1-13.0)$ & $23.4(7.4-32.6)$ & $5.9(3.1-12.5)$ & 0.050 \\
\hline TEG, native $\mathrm{r}$ (minutes) $(\mathrm{n}=47)$ & $7.2(5.9-8.4)$ & $7.1(5.8-9.3)$ & $7.2(5.9-8.4)$ & 0.863 \\
\hline TEG, native MA $(\mathrm{mm})(\mathrm{n}=47)$ & $68.4(63.0-77.9)$ & $73.0(61.4-79.6)$ & $67.9(63.0-77.9)$ & 0.809 \\
\hline TEG, native $\mathrm{CI}(\mathrm{n}=47)$ & $0.8(-1.2-2.3)$ & $0.10(-1.85-3.15)$ & $0.95(-1.20-2.23)$ & 0.904 \\
\hline TEG, native TPI $(\mathrm{mm} / \mathrm{min})(\mathrm{n}=47)$ & $145(93-250)$ & $150(79-399)$ & $138(94-246)$ & 0.945 \\
\hline TEG, native TDR $\left(\mathrm{mm}^{\mathrm{a}}\right.$ degrees $\left./ \mathrm{min}\right)(\mathrm{n}=47)$ & $719(494-898)$ & $579(458-985)$ & $726(491.899)$ & 0.890 \\
\hline CAT, nAPC-SR $(n=49)$ & $2.65(1.04-3.83)$ & $2.73(0.89-3.98)$ & $2.57(1.03-3.87)$ & 0.934 \\
\hline CAT, nETP $(\%)(n=49)$ & $93.9(79.3-107.0)$ & $95.9(81.8-110.7)$ & $93.6(79.0-107.8)$ & 0.704 \\
\hline CAT, nLagtime $(\%)(\mathrm{n}=49)$ & $127.2(109.0-155.0)$ & $136.2(122.6-177.1)$ & $122.7(105.6-155.2)$ & 0.321 \\
\hline CAT, nPeak $(\%)(n=49)$ & $113.2(92.3-128.7)$ & $100.5(88.4-133.0)$ & $114.7(94.0-129.3)$ & 0.632 \\
\hline CAT, nVelIndex $(\%)(n=49)$ & $100.0(85.3-116.1)$ & $114.3(93.3-129.5)$ & $100.0(83.6-116.2)$ & 0.321 \\
\hline CAT, nttpeak $(\%)(n=49)$ & $155.6(117.5-209.9)$ & $130.2(107.9-217.9)$ & $158.1(117.0-210.2)$ & 0.692 \\
\hline CAT, nStart tail $(\%)(\mathrm{n}=49)$ & $102.1(92.8-112.4)$ & $104.2(101.7-113.7)$ & $102.1(92.0-112.3)$ & 0.346 \\
\hline $\mathrm{MPa}(\mathrm{nM})(\mathrm{n}=50)$ & $4.75(2.53-7.73)$ & $6.60(2.75-18.05)$ & $4.70(2.45-7.60)$ & 0.409 \\
\hline MP-TFa (pg/ml)(n=50) & $5.45(2.28-9.78)$ & $5.20(2.75-43.4)$ & $5.70(2.25-9.45$ & 0.650 \\
\hline \multicolumn{5}{|l|}{ Peak coagulation tests } \\
\hline $\mathrm{aFXa}(\mathrm{IU} / \mathrm{ml})(\mathrm{n}=50)$ & $0.21(0.13-0.29)$ & $0.18(0.11-0.31)$ & $0.21(0.14-0.28)$ & 0.722 \\
\hline D-Dimer $(\mu \mathrm{g} / \mathrm{ml})(\mathrm{n}=50)$ & $7.2(3.7-12.9)$ & $18.0(7.3-28.0)$ & $6.1(3.3-12.3)$ & 0.073 \\
\hline TEG, native $r$ (minutes) $(n=41)$ & $9.4(8.2-12.4)$ & $10.7(8.0-13.3)$ & $9.4(8.2-12.4)$ & 0.796 \\
\hline TEG, native MA $(\mathrm{mm})(\mathrm{n}=41)$ & $65.5(59.9-75.4)$ & $71.8(62.4-79.2)$ & $65.0(59.7-75.8)$ & 0.319 \\
\hline TEG, native $\mathrm{CI}(\mathrm{n}=41)$ & $2.2(1.8-3.7)$ & $-0.5(-7.8-0.5)$ & $-2.0(-5.3-0.5)$ & 0.966 \\
\hline TEG, native TPI $(\mathrm{mm} / \mathrm{min})(\mathrm{n}=41)$ & $45(29-57)$ & $43(19-62)$ & $47(32-58)$ & 0.705 \\
\hline TEG, native TDR $\left(\mathrm{mm}^{\mathrm{a}}\right.$ degrees $\left./ \mathrm{min}\right)(\mathrm{n}=41)$ & $421(224-593)$ & $497(199-631)$ & $420(219-594)$ & 0.842 \\
\hline CAT, nETP $(\%)(n=41)$ & $53.6(28.4-76.2)$ & $62.7(22.6-73.9)$ & $52.8(29.7-78.2)$ & 0.704 \\
\hline CAT, nLagtime $(\%)(n=41)$ & $254.2(193.1-347.4)$ & $363.2(231.6-479.2)$ & $244.2(187.3-322.2)$ & 0.811 \\
\hline CAT, nPeak $(\%)(\mathrm{n}=41)$ & $45.9(18.9-76.2)$ & $47.5(2.7-64.4)$ & $43.7(21.0-78.9)$ & 0.169 \\
\hline CAT, nVelIndex $(\%)(n=41)$ & $186.5(147.8-273.0)$ & $272.9(172.1-311.4)$ & $182.0(141.5-238.2)$ & 0.633 \\
\hline CAT, nttpeak $(\%)(n=41)$ & $41.0(13.1-87.7)$ & $37.2(7.3-71.6)$ & $44.7(13.6-95.9)$ & 0.209 \\
\hline CAT, nStart tail $(\%)(\mathrm{n}=41)$ & $136.5(121.6-168.6)$ & $167.5(129.1-172.8)$ & $129.2(118.2-162.8)$ & 0.524 \\
\hline MP-a $(n M)(n=49)$ & $1.2(1.2-1.2)$ & $1.2(1.2-3.5)$ & $1.2(1.2-1.2)$ & 0.004 \\
\hline MP-TFa $(\mathrm{pg} / \mathrm{ml})(\mathrm{n}=49)$ & $1.2(1.2-1.2)$ & $1.2(1.2-2.4)$ & $1.2(1.2-1.2)$ & 0.018 \\
\hline
\end{tabular}

Categorical data are presented as number (\%) and compared using two-sided Pearson's Chi square or Fisher's exact test. Continuous data are presented as median (interquartile range) and compared using two-tailed Mann-Whitney U test, or mean ( \pm standard deviation) and compared using two-sided independent sample T test. Abbreviations: VTE: venous thromboembolism, BMI: body mass index, IU: international units, SAPS: Simplified Acute Physiology Score, AKI: acute kidney injury, RRT: renal replacement therapy, DVT: deep vein thrombosis, PE: pulmonary embolism, ICU: intensive care unit, LOS: length of stay, INR: international normalized ratio, APTT: activated prothrombin time, aFXa: anti-factor Xa activity,TEG: thormbelastography, r: reaction time, MA: maximum amplitude, CI: coagulation index, TPI: thrombodynamic potential index, TDR: thrombodynamic ratio, CAT: calibrated automated thrombogram, nETP: normalized endogenous thrombin potential, nLagtime: normalized lag time, nPeak: normalized peak, nVelIndex: normalized velocity index, nttpeak: normalized time to peak; nStart tail: normalized time to tail, MPa: Microparticles procoagulant activity; MP-TFa: Tissue Factor-bearing microparticles procoagulant activity. n.a.: not applicable. 


\section{Appendix S1}

\section{Timing of coagulation samples}

We obtained additional blood samples for the purpose of this study short time before (trough level) and 3-4 hours after (peak level) administration of prophylactic subcutaneous dalteparin.

\section{Collection of coagulation samples}

Samples were drawn from an arterial or central venous line after appropriate aspiration using completely filled coagulation tubes containing $0.105 \mathrm{M}$ buffered trisodium citrate solution (BD, Belliver Industrial Estate, Plymouth, UK). We gently inverted tubes to ensure that they were adequately mixed. Thromboelastography (TEG) analysis was processed within 5 minutes after sampling; remaining tubes were centrifuged $\left(2500 \mathrm{RCF}, 20\right.$ minutes, $\left.20^{\circ} \mathrm{C}\right)$ before pooled and thereafter aliquoted and stored in micro tubes (Sarstedt, Nümbrecht, Germany) at $-70^{\circ} \mathrm{C}$ for later analyses.

\section{Analyses of coagulation samples}

Antithrombin (AT), protein C activity (PC) and anti-factor Xa activity (aFXa) were quantified by automated chromogenic assays using ACLTOP 700 analyser (Instrumentation Laboratory, Bedford, MA, USA). HemosIL® Liquid Antithrombin reagents, HemosIL® Protein C reagents, calibrators and controls from the same manufacturer were used for measuring respectively AT activity and PC activity. Liquid Anti-Xa reagents, calibrator and controls from Diagnostica Stago (Asnières, France) were used for measuring aFXa activity. D-Dimer 
was measured using the enzyme-linked immunosorbent assay (ELISA) kit Asserachrom ${ }^{\circledR}$ DDi from Diagnostica Stago (Asnières, France).

TEG assays were processed using the Haemoscope TEG 5000 Thromboelastograph haemostasis analyser (Haemonetics Corporation, Skokie, Illinois, USA). Routine quality control, standard calibration, electrical quality control and analyses were performed according to the manufactures' guidelines. Two TEG disposable cups and pins were placed in parallel in the analyser warmed to $37.0^{\circ} \mathrm{C}$, one sample in unmodified kaolin cups, and one sample modified with kaolin-heparinase. In addition to measured values, we calculated the thrombodynamic potential index (TPI) and thrombodynamic ratio (TDR).

The endogenous thrombin potential (ETP) is defined as the time integral of thrombin formation in plasma, i.e. the total amount of free thrombin present from the point of initiation of thrombin formation to the return to baseline. The ETP curve was assayed using the Calibrated Automated Thrombogram (CAT) assay essentially as described by Hemker et al. [14] and according to the user manual provided by Diagnostica Stago (Asnières, France). From the CAT assay we obtained the following parameters: (i) ETP, the area under the thrombin generation curve; (ii) Lag-Time, the time interval between the start of the CAT assay and the onset of thrombin generation; (iii) Peak, the maximum concentration of thrombin; (iv) the velocity index which reflects the rate of thrombin formation, (v) Time-toPeak, the time required to reach maximum thrombin concentration and (vi) Start-Tail, the time interval of the end of the thrombin generation. Coagulation was triggered by recalcification of citrated plasma in the presence of $5 \mathrm{pM}$ recombinant, relipidated human tissue factor (PPP-reagent, Diagnostica Stago, Asnières, France), and $417 \mu \mathrm{M}$ fluorogenic substrate (FluCa, Diagnostica Stago, Asnières, France). Fluorescence was monitored using the Fluoroscan fluorometer (ThermoLabsystems, Helsinki, Finland), and the thrombin generation parameters were calculated using the Thrombinoscope software (Diagnostica Stago, Asnières, 
France). In order to increase reproducibility, all CAT-derived parameters were normalised by dividing the measured test value with that of reference plasma pooled from 34 healthy adults run in the same assay.

The microparticles (MPs) were assayed in 96-wells micro plate using the functional assay Zymuphen ${ }^{\mathrm{TM}}$ MP activity kit (Hyphen Biomed, Neuville-sur-Oise, France), and the Spectramax ${ }^{\circledR}$ plus384 spectrophotometer (Molecular Devices, San Jose, CA, USA). Results were calculated using the SoftMax ${ }^{\circledR}$ Pro Software (Molecular Devices, San Jose, CA, USA). The lower limit of detection is $1.5 \mathrm{nM}$. The MPa exposing Tissue Factor were assayed in 96wells micro plate using the functional assay Zymuphen ${ }^{\mathrm{TM}}$ MP-TF kit (Hyphen Biomed, Neuville-sur-Oise, France) and the Spectramax ${ }^{\circledR}$ plus384 spectrophotometer (Molecular Devices, San Jose, CA, USA). Results were calculated using the SoftMax ${ }^{\circledR}$ Pro Software (Molecular Devices, San Jose, CA, USA). The lower limit of detection is $1.3 \mathrm{pg} / \mathrm{mL}$. 


\section{Appendix S2}

Correlation between administered dalteparin dose and peak thromboelastography (TEG) native reaction (r) time

Scatter plot of administrated dalteparin dose (IU/kg bodyweight) and peak TEG native reaction time (r) (seconds) $(n=47)$

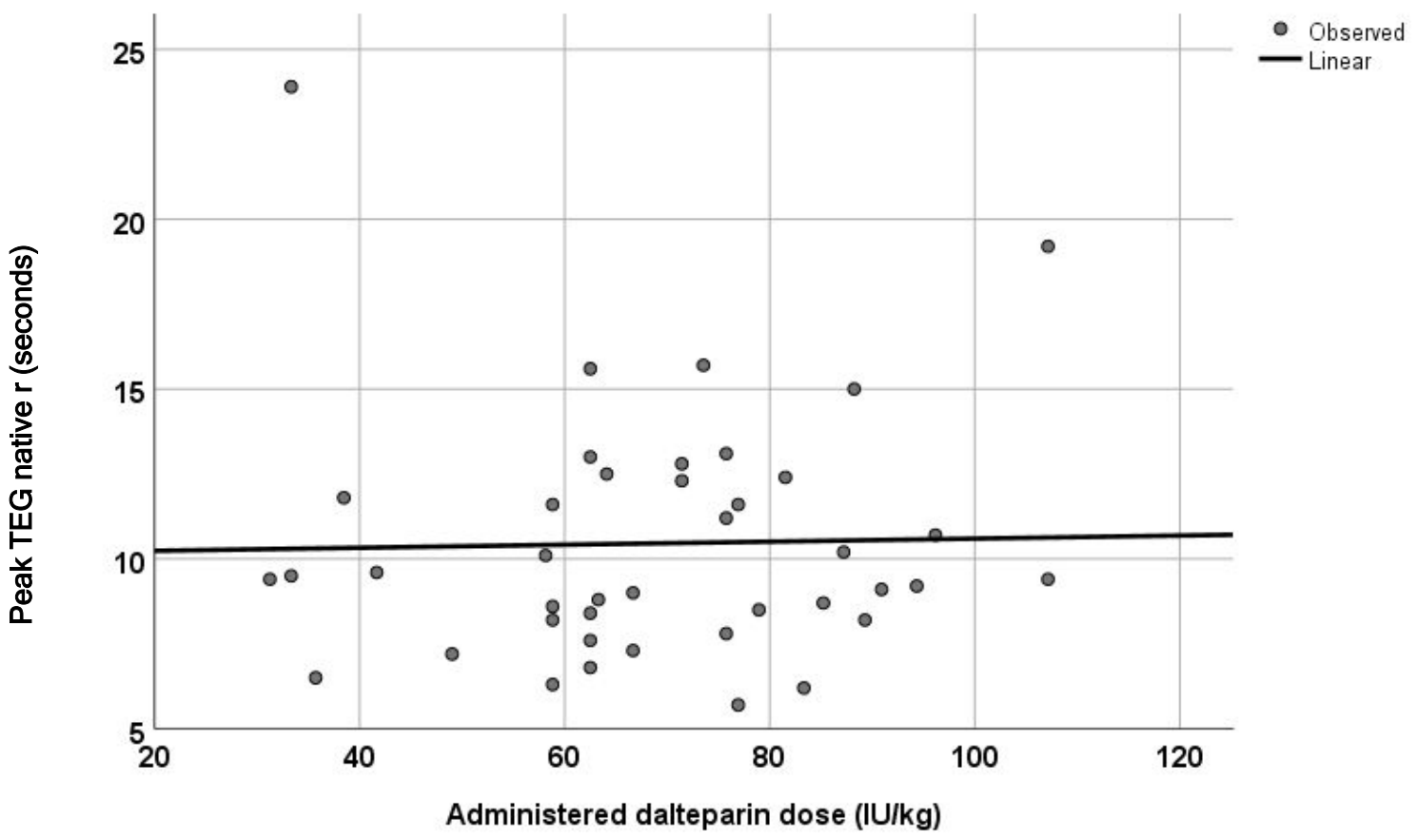

Variables were not significantly correlated, $\mathrm{r}=0.024, \mathrm{p}=0.882$ 


\section{Appendix S3}

Correlation between administered dalteparin dose and peak normalized endogenous thrombin potential

Scatter plot of administrated dalteparin dose (IU/kg bodyweight) and peak normalized endogenous thrombin potential (nETP) (\%) at the calibrated automated thrombogram $(C A T)(n=41)$

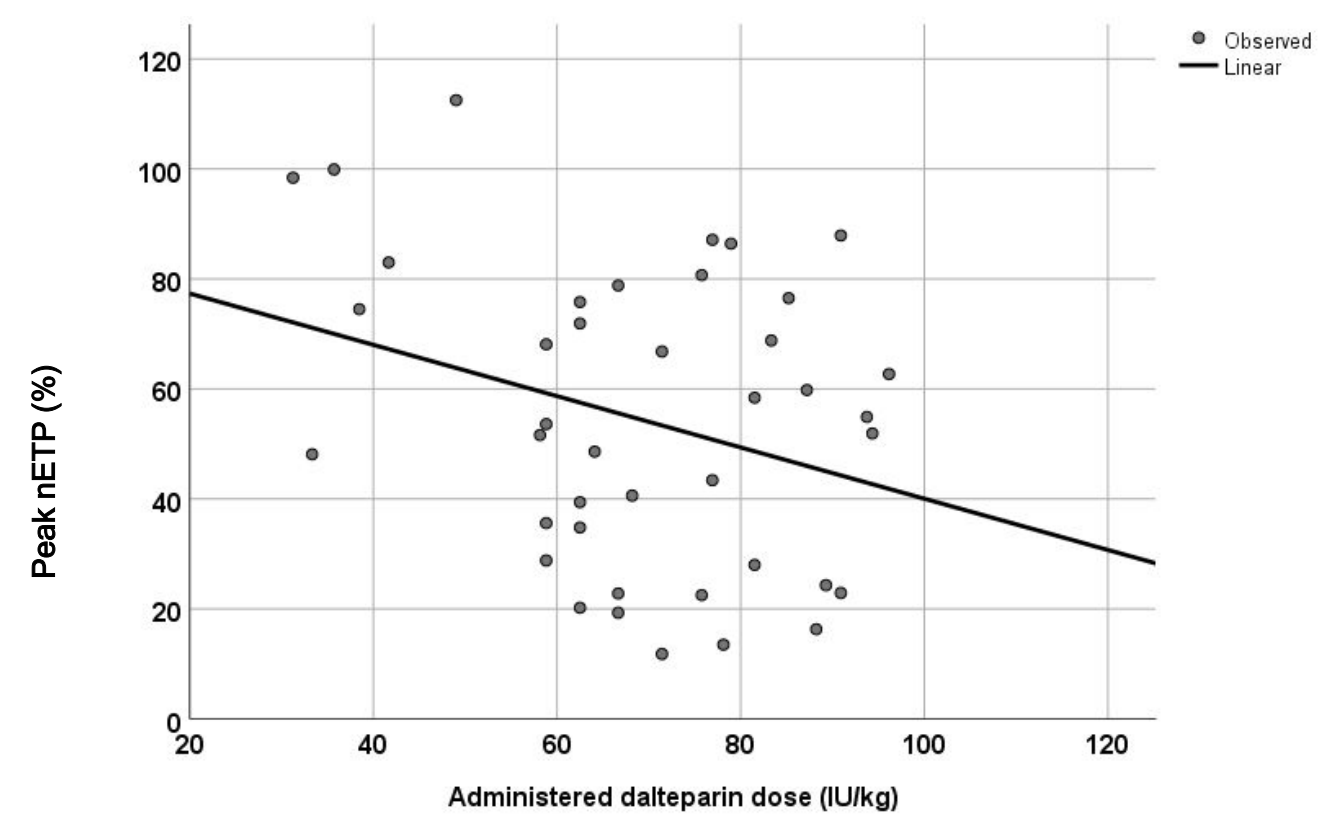

Variables were not significantly correlated, $r=0.299, p=0.058$ 
Appendix S5

Coagulation analyses in intensive care unit patients with and without acute kidney injury and renal replacement therapy

\begin{tabular}{|c|c|c|c|c|}
\hline Patient data & $\begin{array}{l}\text { All included } \\
\text { patients } \\
(n=50)\end{array}$ & $\begin{array}{c}\text { Patients } \\
\text { with AKI and RRT } \\
(n=25)\end{array}$ & $\begin{array}{c}\text { Patients } \\
\text { without AKI and } \\
\text { RRT }(n=25)\end{array}$ & $\begin{array}{c}\text { p- } \\
\text { value }\end{array}$ \\
\hline Age, years & $62.0( \pm 11.6)$ & $63.7( \pm 12.4)$ & $60.3( \pm 2.2)$ & 0.307 \\
\hline Male sex & $38(76.0)$ & $18(72.0)$ & $20(80.0)$ & 0.508 \\
\hline Surgical admission & $36(72.0)$ & $19(76.0)$ & $17(68.0)$ & 0.529 \\
\hline Any comorbidity & $36(72.0)$ & $18(72.0)$ & $18(72.0)$ & 1.000 \\
\hline BMI, kilogram/square meters & $24.6( \pm 3.6)$ & $25.0( \pm 4.0)$ & $24.3( \pm 3.2)$ & 0.476 \\
\hline Dalteparin dose, IU (blood sample day) & $5600( \pm 1562)$ & $5500( \pm 1614)$ & $5700( \pm 1534)$ & 0.665 \\
\hline Dalteparin dose, IU/kg (blood sample day) & $70.5( \pm 18.5)$ & $68.9( \pm 20.8)$ & $72.0( \pm 63.3)$ & 0.551 \\
\hline SAPS II, score & $43.2( \pm 16.7)$ & $49.2( \pm 14.4)$ & $37.3( \pm 17.0)$ & 0.011 \\
\hline VTE & $5(10)$ & $4(16.0)$ & $1(4.0)$ & 0.157 \\
\hline DVT & $5(10)$ & $4(16.0)$ & $1(4.0)$ & 0.157 \\
\hline $\mathrm{PE}$ & $0(0)$ & $0(0.0)$ & $0(0.0)$ & n.a. \\
\hline Any bleeding & $21(42)$ & $12(48.0)$ & $17(68.0)$ & 0.152 \\
\hline Major bleeding & $8(16)$ & $4(16.0)$ & $4(16.0)$ & 1.000 \\
\hline ICU LOS & $11.0(7.8-20.0)$ & $13.0(8.0-36.0)$ & $9.0(7.0-14.0)$ & 0.102 \\
\hline ICU mortality & $9(18.0)$ & $5(20.0)$ & $4(16.0)$ & 0.713 \\
\hline \multicolumn{5}{|l|}{ Conventional coagulation tests } \\
\hline Routine platelets $\left(\times 10^{9}\right.$ cells $\left./ 1\right)(\mathrm{n}=50)$ & $171(94-271)$ & $95(77-187)$ & $239(171-324)$ & $<0.001$ \\
\hline Routine INR $(\mathrm{n}=40)$ & $1.15(1.10-1.28)$ & $1.20(1-10-1.38)$ & $1.10(1.00-1.18)$ & 0.002 \\
\hline Routine APTT (seconds) $(\mathrm{n}=25)$ & $42(38-46)$ & $43(38-48)$ & $42(38-43)$ & 0.559 \\
\hline Routine fibrinogen $(g / 1)(n=23)$ & $5.7(3.6-6.9)$ & $5.7(3.5-6.8)$ & $6.1(3.8-7.5)$ & 0.575 \\
\hline \multicolumn{5}{|l|}{ Trough coagulation tests } \\
\hline Antithrombin $(\%)(n=50)$ & $82.0(71.7-99.4)$ & $76.0(61.2-89.0)$ & $93.7(79.3-107.5)$ & 0.004 \\
\hline Protein $C(\%)(n=50)$ & $77.8(56.9-106.4)$ & $70.8(52.3-85.1)$ & $97.3(62.3-116.6)$ & 0.130 \\
\hline $\mathrm{aFXa}(\mathrm{IU} / \mathrm{ml})(\mathrm{n}=50)$ & $0.03(0.02-0.05)$ & $0.03(0.02-0.04)$ & $0.04(0.02-0.05)$ & 0.473 \\
\hline D-Dimer $(\mu \mathrm{g} / \mathrm{ml})(\mathrm{n}=50)$ & $7.7(3.1-13.0)$ & $8.3(3.8-19.5)$ & $5.5(1.9-11.8)$ & 0.109 \\
\hline TEG, native $r$ (minutes) $(n=47)$ & $7.2(5.9-8.4)$ & $6.9(5.6-8.4)$ & $7.2(6.0-8.4)$ & 0.587 \\
\hline TEG, native MA $(\mathrm{mm})(\mathrm{n}=47)$ & $68.4(63.0-77.9)$ & $65.9(61.6-76.6)$ & $70.3(64.3-78.9)$ & 0.163 \\
\hline TEG, native CI $(n=47)$ & $0.8(-1.2-2.3)$ & $0.3(-1.8-2.9)$ & $1.2(01.0-2.0)$ & 0.631 \\
\hline TEG, native TPI $(\mathrm{mm} / \mathrm{min})(\mathrm{n}=47)$ & $145(93-250)$ & $104(89-252)$ & $166(106-247)$ & 0.245 \\
\hline TEG, native TDR $\left(\mathrm{mm}^{\text {a degrees }} / \mathrm{min}\right)(\mathrm{n}=47)$ & $719(494-898)$ & $655(452-950)$ & $733(518-833)$ & 0.881 \\
\hline CAT, nAPC-SR $(n=49)$ & $2.65(1.04-3.83)$ & $1.89(0.68-3.24)$ & $2.73(1.08-4.19)$ & 0.150 \\
\hline CAT, nETP $(\%)(n=49)$ & $93.9(79.3-107.0)$ & $87.2(75.3-95.8)$ & $99.9(87.2-111.7)$ & 0.005 \\
\hline CAT, nLagtime $(\%)(n=49)$ & $127.2(109.0-155.0)$ & $140.1(111.3-180.7)$ & $118.0(104.4-136.7)$ & 0.037 \\
\hline CAT, nPeak $(\%)(n=49)$ & $113.2(92.3-128.7)$ & $100.5(84.5-166.6)$ & $120.0(105.5-145.2)$ & 0.002 \\
\hline CAT, nVelIndex $(\%)(n=49)$ & $100.0(85.3-116.1)$ & $114.2(92.1-133.6)$ & $91.0(83.8-109.6)$ & 0.048 \\
\hline CAT, nttpeak $(\%)(n=49)$ & $155.6(117.5-209.9)$ & $127.9(106.5-196.2)$ & $175.9(139.6-230.2)$ & 0.021 \\
\hline CAT, nStart tail $(\%)(n=49)$ & $102.1(92.8-112.4)$ & $107.0(93.4-116.8)$ & $102.1(91.2-105.6)$ & 0.126 \\
\hline $\operatorname{MPa}(\mathrm{nM})(\mathrm{n}=50)$ & $4.75(2.53-7.73)$ & $4.70(3.05-7.60)$ & $5.60(2.25-7.75)$ & 0.621 \\
\hline MP-TFa $(\mathrm{pg} / \mathrm{ml})(\mathrm{n}=50)$ & $5.45(2.28-9.78)$ & $5.10(2.10-7.10)$ & $7.40(2.30-13.6)$ & 0.210 \\
\hline \multicolumn{5}{|l|}{ Peak coagulation tests } \\
\hline $\mathrm{aFXa}(\mathrm{IU} / \mathrm{ml})(\mathrm{n}=50)$ & $0.21(0.13-0.29)$ & $0.18(0.11-0.30)$ & $0.24(0.19-0.29)$ & 0.130 \\
\hline D-Dimer $(\mu \mathrm{g} / \mathrm{ml})(\mathrm{n}=50)$ & $7.2(3.7-12.9)$ & $7.4(4.4-19.1)$ & $5.3(1.8-10.3)$ & 0.049 \\
\hline TEG, native $r$ (minutes) $(n=41)$ & $9.4(8.2-12.4)$ & $9.6(8.6-12.9)$ & $8.8(7.5-12.1)$ & 0.766 \\
\hline TEG, native MA $(\mathrm{mm})(\mathrm{n}=41)$ & $65.5(59.9-75.4)$ & $66.2(54.8-74.0)$ & $65.2(62.3-76.9)$ & 0.930 \\
\hline TEG, native CI $(n=41)$ & $2.2(1.8-3.7)$ & $-2.5(-7.1-0.3)$ & $-0.7(-4.8-0.5)$ & 0.624 \\
\hline TEG, native TPI $(\mathrm{mm} / \mathrm{min})(\mathrm{n}=41)$ & $45(29-57)$ & $38(21-57)$ & $50(38-57)$ & 0.001 \\
\hline TEG, native TDR $\left(\mathrm{mm}^{\text {a degrees }} / \mathrm{min}\right)(\mathrm{n}=41)$ & $421(224-593)$ & $369(131-546)$ & $490(305-615)$ & 0.060 \\
\hline CAT, $\operatorname{nETP}(\%)(n=41)$ & $53.6(28.4-76.2)$ & $43.4(22.9-71.9)$ & $59.1(35.4-82.1)$ & 0.191 \\
\hline CAT, nLagtime $(\%)(n=41)$ & $254.2(193.1-347.4)$ & $245.2(195.4-508.7)$ & $258.9(189.6-324.6)$ & 0.666 \\
\hline CAT, nPeak $(\%)(n=41)$ & $45.9(18.9-76.2)$ & $40.3(15.0-78.0)$ & $52.9(21.7-75.8)$ & 0.464 \\
\hline CAT, nVelIndex $(\%)(n=41)$ & $186.5(147.8-273.0)$ & $177.4(140.9-329.7)$ & $186.5(150.1-251.4)$ & 0.696 \\
\hline CAT, nttpeak $(\%)(n=41)$ & $41.0(13.1-87.7)$ & $35.1(8.3-97.6)$ & $53.6(15.6-83.8)$ & 0.565 \\
\hline CAT, nStart tail $(\%)(n=41)$ & $136.5(121.6-168.6)$ & $139.8(110.3-174.9)$ & $128.4(123.6-160.7)$ & 0.583 \\
\hline $\operatorname{MPa}(\mathrm{nM})(\mathrm{n}=49)$ & $1.2(1.2-1.2)$ & $1.2(1.2-1.2)$ & $1.2(1.2-1.2)$ & 0.255 \\
\hline MP-TFa $(\mathrm{pg} / \mathrm{ml})(\mathrm{n}=49)$ & $1.2(1.2-1.2)$ & $1.2(1.2-1.2)$ & $1.2(1.2-1.2)$ & 0.703 \\
\hline
\end{tabular}

Categorical data are presented as number (\%) and compared using two-sided Pearson's Chi square or Fisher's exact test. Continuous data are presented as median (interquartile range) and compared using two-tailed Mann-Whitney U test, or mean ( \pm standard deviation) and compared using two-sided independent sample T test. Abbreviations: AKI: acute kidney injury, RRT: renal replacement therapy, BMI: body mass index, IU: international units, SAPS: Simplified Acute Physiology Score, VTE: venous thromboembolism, DVT: deep vein thrombosis, PE: pulmonary embolism, ICU: intensive care unit, LOS: length of stay, INR: international normalized ratio, APTT: activated prothrombin time, aFXa: anti-factor Xa activity,TEG: thormbelastography, r: reaction time, MA: maximum amplitude, CI: coagulation index, TPI: thrombodynamic potential index, TDR: thrombodynamic ratio, CAT: calibrated automated thrombogram, nETP: normalized endogenous thrombin potential, nLagtime: normalized lag time, nPeak: normalized peak, nVelIndex: normalized velocity index, nttpeak: normalized time to peak; nStart tail: normalized time to tail, MPa: Microparticles procoagulant activity; MP-TFa: Tissue Factor-bearing microparticles procoagulant activity. 


\section{Appendix S6}

Coagulation analyses in intensive care unit patients with variable dalteparin dose

\begin{tabular}{|c|c|c|c|c|}
\hline Patient data & $\begin{array}{l}\text { All included } \\
\text { patients } \\
(\mathbf{n}=\mathbf{5 0})\end{array}$ & $\begin{array}{c}\text { Dalteparin } \\
5000 \text { IUx1 } \\
(n=28)\end{array}$ & $\begin{array}{c}\text { Dalteparin } \\
7500 \text { IUx1 } \\
(n=17)\end{array}$ & $\begin{array}{c}\text { p- } \\
\text { value* }\end{array}$ \\
\hline Age, years & $62.0( \pm 11.6)$ & $60.9( \pm 12.1)$ & $64.1( \pm 11.6)$ & 0.382 \\
\hline Male sex & $38(76.0)$ & $24(85.7)$ & $13(76.5)$ & 0.452 \\
\hline BMI, kilogram/square meters & $24.6( \pm 3.6)$ & $23.8( \pm 3.9)$ & $26.2( \pm 2.8)$ & 0.032 \\
\hline Surgical admission & $36(72.0)$ & $18(64.3)$ & $16(94.1)$ & 0.033 \\
\hline Any comorbidity & $36(72.0)$ & $19(67.9)$ & $13(76.5)$ & 0.737 \\
\hline SAPS II, score & $43.2( \pm 16.7)$ & $45.2( \pm 18.4)$ & $38.4( \pm 14.0)$ & 0.197 \\
\hline Dalteparin dose, IU/kg (blood sample day) & $70.5( \pm 18.5)$ & $67.2( \pm 13.4)$ & $85.7( \pm 10.6)$ & $<0.001$ \\
\hline AKI with RRT & $25(50.0)$ & $14(50.0)$ & $8(47.1)$ & 0.850 \\
\hline DVT & $5(10.0)$ & $3(10.7)$ & $2(11.8)$ & 1.000 \\
\hline $\mathrm{PE}$ & $0(0.0)$ & $0(0.0)$ & $0(0.0)$ & n.a. \\
\hline Any bleeding & $21(42.0)$ & $14(50.0)$ & $4(23.5)$ & 0.079 \\
\hline Major bleeding & $8(16.0)$ & $8(28.6)$ & $0(0.0)$ & 0.017 \\
\hline ICU LOS & $11.0(7.8-20.0)$ & $10.5(8.0-19.8)$ & $13.0(7.5-20.5)$ & 0.751 \\
\hline ICU mortality & $9(18.0)$ & $7(25.0)$ & $1(5.9)$ & 0.132 \\
\hline \multicolumn{5}{|l|}{ Conventional coagulation tests } \\
\hline Routine platelets $\left(\mathrm{x} 10^{9}\right.$ cells $\left./ \mathrm{l}\right)(\mathrm{n}=50)$ & $171(94-271)$ & $160(94-227)$ & $257(97-380)$ & 0.109 \\
\hline Routine INR $(n=40)$ & $1.15(1.10-1.28)$ & $1.20(1.10-1.20)$ & $1.10(1.10-1.33)$ & 0.947 \\
\hline Routine APTT (seconds) $(\mathrm{n}=25)$ & $42(38-46)$ & $43.0(38.0-46.0)$ & $42.0(37.0-43.0)$ & 0.502 \\
\hline Routine fibrinogen $(g / 1)(n=23)$ & $5.7(3.6-6.9)$ & $5.0(3.5-6.6)$ & $6.5(4.9-7.1)$ & 0.192 \\
\hline \multicolumn{5}{|l|}{ Trough coagulation tests } \\
\hline Antithrombin $(\%)(n=50)$ & $82.0(71.7-99.4)$ & $81.7(71.5-100.0)$ & $91.7(75.0-108.9)$ & 0.314 \\
\hline Protein $\mathrm{C}(\%)(\mathrm{n}=50)$ & $77.8(56.9-106.4)$ & $77.1(57.7-106.8)$ & $85.1(56.0-113.4)$ & 0.851 \\
\hline $\mathrm{aFXa}(\mathrm{IU} / \mathrm{ml})(\mathrm{n}=50)$ & $0.03(0.02-0.05)$ & $0.04(0.02-0.05)$ & $0.03(0.03-0.07)$ & 0.373 \\
\hline D-Dimer $(\mu \mathrm{g} / \mathrm{ml})(\mathrm{n}=50)$ & $7.7(3.1-13.0)$ & $4.9(2.1-11.9)$ & $7.8(4.5-18.1)$ & 0.106 \\
\hline TEG, native $r$ (minutes) $(n=47)$ & $7.2(5.9-8.4)$ & $7.2(5.7-8.4)$ & $7.1(5.4-8.4)$ & 0.773 \\
\hline TEG, native MA $(\mathrm{mm})(\mathrm{n}=47)$ & $68.4(63.0-77.9)$ & $64.6(62.7-73.3)$ & $77.8(68.4-79.9)$ & 0.005 \\
\hline TEG, native CI $(n=47)$ & $0.8(-1.2-2.3)$ & $0.8(-1.3-2.1)$ & $1.7(-1.2-3.4)$ & 0.294 \\
\hline TEG, native TPI $(\mathrm{mm} / \mathrm{min})(\mathrm{n}=47)$ & $145(93-250)$ & $114(90-242)$ & $195(106-320)$ & 0.068 \\
\hline TEG, native TDR $\left(\mathrm{mm}^{\text {adegrees}} / \mathrm{min}\right)(\mathrm{n}=47)$ & $719(494-898)$ & $733(482-858)$ & $776(500-1058)$ & 0.439 \\
\hline CAT, nAPC-SR $(\mathrm{n}=49)$ & $2.65(1.04-3.83)$ & $2.22(0.92-3.18)$ & $3.47(1.55-4.53)$ & 0.048 \\
\hline CAT, $\operatorname{nETP}(\%)(n=49)$ & $93.9(79.3-107.0)$ & $89.7(75.7-100.4)$ & $96.9(83.9-113.8)$ & 0.117 \\
\hline CAT, nLagtime $(\%)(\mathrm{n}=49)$ & $127.2(109.0-155.0)$ & $118.0(100.0-140.5)$ & $140.9(122.6-200.2)$ & 0.009 \\
\hline CAT, nPeak $(\%)(n=49)$ & $113.2(92.3-128.7)$ & $107.2(86.0-120.0)$ & $120.0(100.5-141.3)$ & 0.073 \\
\hline CAT, nVelIndex $(\%)(n=49)$ & $100.0(85.3-116.1)$ & $94.3(81.5-114.4)$ & $114.2(88.7-138.7)$ & 0.061 \\
\hline CAT, nttpeak $(\%)(\mathrm{n}=49)$ & $155.6(117.5-209.9)$ & $148.7(108.7-197.4)$ & $189.0(121.1-232.8)$ & 0.120 \\
\hline CAT, nStart tail $(\%)(n=49)$ & $102.1(92.8-112.4)$ & $102.1(93.2-110.7)$ & $102.1(91.5-116.7)$ & 0.824 \\
\hline $\operatorname{MPa}(\mathrm{nM})(\mathrm{n}=50)$ & $4.75(2.53-7.73)$ & $4.25(2.38-7.26)$ & $5.80(4.05-7.60)$ & 0.468 \\
\hline MP-TFa $(\mathrm{pg} / \mathrm{ml})(\mathrm{n}=50)$ & $5.45(2.28-9.78)$ & $7.10(2.08-13.48)$ & $5.20(2.65-7.50)$ & 0.419 \\
\hline \multicolumn{5}{|l|}{ Peak coagulation tests } \\
\hline $\mathrm{aFXa}(\mathrm{IU} / \mathrm{ml})(\mathrm{n}=50)$ & $0.21(0.13-0.29)$ & $0.19(0.13-0.24)$ & $0.30(0.24-0.37)$ & 0.001 \\
\hline Peak D-Dimer $(\mu \mathrm{g} / \mathrm{ml})(\mathrm{n}=50)$ & $7.2(3.7-12.9)$ & $5.3(2.5-10.6)$ & $8.9(4.5-18.7)$ & 0.111 \\
\hline TEG, native $r$ (minutes) $(n=41)$ & $9.4(8.2-12.4)$ & $9.2(8.2-12.2)$ & $10.5(8.6-12.9)$ & 0.421 \\
\hline TEG, native MA $(\mathrm{mm})(\mathrm{n}=41)$ & $65.5(59.9-75.4)$ & $65.4(60.2-74.0)$ & $68.6(58.0-77.7)$ & 0.638 \\
\hline TEG, native CI $(\%)(n=41)$ & $2.2(1.8-3.7)$ & $-1.9(-6.4-0.9)$ & $-1.3(-4.7-0.2)$ & 0.985 \\
\hline TEG, native TPI $(\mathrm{mm} / \mathrm{min})(\mathrm{n}=41)$ & $45(29-57)$ & $47(23-56)$ & $44(33-53)$ & 0.906 \\
\hline TEG, native TDR $\left(\mathrm{mm}^{\mathrm{a}}\right.$ degrees $\left./ \mathrm{min}\right)(\mathrm{n}=41)$ & $421(224-593)$ & $408(219-630)$ & $453(242-562)$ & 0.946 \\
\hline $\mathrm{CAT}, \operatorname{nETP}(\%)(\mathrm{n}=41)$ & $53.6(28.4-76.2)$ & $48.6(23.6-73.2)$ & $59.1(31.2-74.6)$ & 0.475 \\
\hline CAT, nLagtime $(\%)(\mathrm{n}=41)$ & $254.2(193.1-347.4)$ & $245.0(193.1-322.2)$ & $322.5(247.5-493.9)$ & 0.050 \\
\hline CAT, nPeak $(\%)(n=41)$ & $45.9(18.9-76.2)$ & $35.6(15.3-79.2)$ & $47.3(25.6-67.3)$ & 0.673 \\
\hline CAT, nVelIndex $(\%)(n=41)$ & $186.5(147.8-273.0)$ & $117.4(151.9-258.6)$ & $212.1(170.3-326.5)$ & 0.153 \\
\hline CAT, nttpeak $(\%)(n=41)$ & $41.0(13.1-87.7)$ & $26.6(9.4-102.8)$ & $48.1(20.0-68.3)$ & 0.559 \\
\hline CAT, nStart tail $(\%)(n=41)$ & $136.5(121.6-168.6)$ & $136.5(121.6-165.7)$ & $142.6(127.3-178.5)$ & 0.284 \\
\hline $\operatorname{MPa}(n M)(n=49)$ & $1.2(1.2-1.2)$ & $1.2(1.2-1.2)$ & $1.2(1.2-1.2)$ & 0.514 \\
\hline MP-TFa $(\mathrm{pg} / \mathrm{ml})(\mathrm{n}=49)$ & $1.2(1.2-1.2)$ & $1.2(1.2-1.2)$ & $1.2(1.2-1.2)$ & 0.428 \\
\hline
\end{tabular}

Categorical data are presented as number (\%) and compared using two-sided Pearson's Chi square or Fisher's exact test. Continuous data are presented as median (interquartile range) and compared using two-tailed Mann-Whitney U test, or mean ( \pm standard deviation) and compared using two-sided independent sample T test. Abbreviations: IU: international units, BMI: body mass index, SAPS: Simplified Acute Physiology Score, AKI: acute kidney injury, RRT: renal replacement therapy, VTE: venous thromboembolism, DVT: deep vein thrombosis, PE: pulmonary embolism, ICU: intensive care unit, LOS: length of stay, INR: international normalized ratio, APTT: activated prothrombin time, aFXa: anti-factor Xa activity,TEG: thormbelastography, r: reaction time, MA: maximum amplitude, CI: coagulation index, TPI: thrombodynamic potential index, TDR: thrombodynamic ratio, CAT: calibrated automated thrombogram, nETP: normalized endogenous thrombin potential, nLagtime: normalized lag time, nPeak: normalized peak, nVelIndex: normalized velocity index, nttpeak: normalized time to peak; nStart tail: normalized time to tail, MPa: Microparticles procoagulant activity; MP-TFa: Tissue Factor-bearing microparticles procoagulant activity. ${ }^{*}=$ p-values are from comparison of dalteparin dose 5000 IUx1 and 7500 IUx1. 